\title{
LA SUGERENTE FIGURA DE LAS MARCAS BLANCAS: NOTAS DESDE EL ORDENAMIENTO JURÍDICO ESPAÑOL
}

\author{
THE SUGGESTIVE FIGURE OF WHITE BRANDS: MARKS FROM THE \\ SPANISH LAW*
}

\section{DAVID LÓPEZ JIMÉNEZ}

\begin{abstract}
RESUMEN: En la actualidad, como la práctica pone de manifiesto, los grandes distribuidores están comercializando un importante número de bienes con su propio sello comercial que compiten con las marcas de fabricantes líderes. Tal figura se ha denominado, con carácter general, marca blanca. Aunque el recurso a tal herramienta resulta plenamente lícito, se ven afectadas ciertas funciones paradigmáticas de la marca. También cabe considerar las particularidades que se plantean, por un lado, desde la perspectiva del Derecho de la competencia y, por otro, de la competencia desleal. A todo ello nos referiremos en el presente artículo de investigación, tomando como base el ordenamiento jurídico español.
\end{abstract}

Palabras clave: Competencia, confusión, desleal, distribución, marcas.

ABSTRACT: Nowadays, as practice shows, big retailers are selling a large number of goods with their own commercial seals that compete with leading manufacturers brands. This figure has been called, in general, white brand. Although the use of such tool is entirely lawful, certain paradigmatic functions of the brand are affected. It is also important to consider peculiarities that arise, one the one hand from the perspective of the competition Law, and on the other hand of unfair competition. To all this we will refer in this research paper, and we will consider as base the Spanish law.

Key words: Competition, confusion, unfair, distribution, marks.

\section{INTRODUCCIÓN}

La gran distribución minorista desempeña en el escenario europeo un papel muy destacado respecto a su contribución a la economía, a la creación de empleo y a la diversificación de la oferta a los consumidores ${ }^{1}$. Además, no debemos olvidar que, como ha quedado probado en repetidos estudios ${ }^{2}$, llevados a cabo por las autoridades nacionales en materia de competencia, la distribución minorista es un sector dinámico, innovador y competitivo. Entre las actuaciones comerciales desarrolladas por el distribuidor destaca, sobre

\footnotetext{
* El autor desea hacer constar su expreso agradecimiento a los evaluadores anónimos que valoraron el presente artículo. Sus enriquecedoras sugerencias permitieron mejorar su contenido.

* Licenciado por la Universidad Complutense de Madrid, España. Doctor (con mención especial europea) por la Universidad de Sevilla, España y Doctor por la Universidad Rey Juan Carlos de Madrid, España. Es profesor investigador de la Universidad Autónoma de Chile. Correo electrónico: david.lopez@uautonoma.cl.

1 Así lo ha puesto de relieve parte de la doctrina económica. En este sentido véase, Ruzo SANMARTín et al. (2004) pp. 1-31; Dawson y Frasquet Deltoro (2006) pp. 11-24.

2 Sobre este particular, cabe destacar el informe publicado en mayo de 2008 por la Comisión de la Competencia del Reino Unido sobre las cadenas de alimentación.
} 
todos a efectos del presente trabajo, la creación y consolidación de productos, elaborados generalmente por otros fabricantes distintos al propio distribuidor, que ostentarán la marca del distribuidor -también denominada marca blanca-. Las prácticas realizadas con respecto a las marcas de distribuidor, en ciertas ocasiones, podrán vulnerar la normativa de defensa de la competencia y de competencia desleal.

Hemos de aclarar que el término "marca blanca" es el que se acuñó, en los albores de la misma, para referirse a bienes que carecían de publicidad en sus envases, diferenciándose, en tal aspecto, frente a las marcas de los fabricantes líderes. Hoy, sin embargo, gozan de tanto colorido como las primeras marcas, por lo que podría carecer de razón de ser tal denominación, siendo más oportuna, por poner un ejemplo, la de marca de distribuidor. En todo caso, tal expresión ha hecho fortuna a nivel coloquial, por lo que, teniendo en cuenta tal premisa, en el presente estudio, emplearemos indistintamente ambos términos -marca blanca y marca de distribuidor-, sin perjuicio de que, insistimos, ha de considerarse la presente matización.

El crecimiento de la marca blanca ha generado un nuevo escenario competitivo: las empresas de la distribución son, al mismo tiempo, distribuidoras y competidoras de los productores/fabricantes ${ }^{3}$. Además, ha de considerarse que la distribución fija tanto el precio final de la marca blanca como del producto del productor/fabricante. Tal extremo puede inducir a la distribución a aumentar los precios de los productos de estos últimos para atraer clientes hacia sus marcas blancas ${ }^{4}$. Entre todas las opciones posibles, el consumidor elegirá el producto más parecido al que le gustaría tener con el menor precio, dentro de cuyo espectro se encuentran las marcas de distribuidor ${ }^{5}$. Precisamente, este último -el precio menor- es la clave que distancia enormemente un producto de marca líder de uno de los de la distribución, tanto que, en algunos casos, sin entrar a valorar la calidad, puede resultar la mitad. Cuando la economía marcha bien no hay problema, pero en épocas de crisis es, en este punto, donde las familias más reducen el coste de la cesta de la compra. Sobre todo si el lineal ${ }^{6}$ premia, como es el caso, a las marcas de la distribución de las del industrial ${ }^{7}$.

Debemos reconocer el inconmensurable poder que, en la actualidad, tienen los distribuidores. En efecto, estos últimos tienen fuerza suficiente como para imponer numerosas condiciones al fabricante, pudiéndose colegir, por tanto, que, hoy por hoy, el poder radica,

\footnotetext{
3 Con el término "productor" o "fabricante" se designa al agente económico que constituye el primer nivel del canal de distribución de un determinado producto.

4 Tal aspecto resulta destacado por el estudio efectuado en 2005 por las autoridades de Competencia de Dinamarca, Groenlandia, Islandia, Islas Feroe, Finlandia, Noruega y Suecia, cuyo título es Nordic Food Markets, a taste for competition.

5 Esta es una de las principales conclusiones que se deducen del estudio DMC-Track que en junio de 2009 ha presentado TNS Consumer sobre las respuestas del consumidor ante la crisis. Tal informe determina que nueve de cada diez españoles acostumbra a comprar marcas de distribuidor, a pesar de que más de la mitad de ellos (un 54\%) declara que no le gusta hacerlo, pero que lo realiza para ahorrar.

${ }^{6}$ En efecto, las marcas controladas por las grandes superficies -las marcas blancas y las exclusivas de la enseñasuelen gozar del privilegio de los llamados "puntos calientes" en los lineales de las cadenas de distribución.

7 Gómez (1995) pp. 26-30.
} 
más que en la fabricación, en la distribución ${ }^{8}$. De hecho, si los proveedores quieren vender ${ }^{9}$ en los establecimientos de los distribuidores, deben acceder a las determinaciones, dentro de ciertos límites ${ }^{10}$, que estos últimos establezcan, entre las que podrán encontrarse las vinculadas con las marcas blancas. Algo similar aconteció, como a continuación veremos, en la venta a pérdida ${ }^{11}$.

Los oferentes de bienes y/o servicios, con la finalidad de desorientar los mecanismos sobre los precios que tienen los consumidores, crean ofertas que operan como señuelo en productos de uso más frecuente. La oferta en cuestión hace que el mecanismo de control del consumidor baje y la única referencia de la que el mismo dispone es la relación comparativa de ese bien o servicio con su experiencia ${ }^{12}$. A partir de este momento, incluso un consumidor medio, atraído por el gancho al establecimiento, seguirá comprando el resto de productos que necesita, en la creencia de que el nivel general de precios es aceptable. Asimismo, el consumidor puede, siendo consciente de que esos concretos productos o servicios tienen un precio anormalmente bajo, decidir continuar su aprovisionamiento.

En este sentido, Bernardo Trujillo señaló que los consumidores, como regla general, conocen el precio de un número determinado de productos, formulando, a finales de la década de los sesenta, la conocida teoría de "islotes de pérdidas en océanos de beneficios"13", en virtud de la cual puede manifestarse que si se bajan los precios de los artículos que el consumidor conoce $^{14}$, creerá, aunque no sea cierto, que todos los precios del establecimiento son más bajos que los de otros competidores, comprando, de este modo, un mayor número de productos. El consumidor medio, consciente o no del engaño, ha terminado, como decimos, comprando en el establecimiento que ha realizado una venta a pérdida señuelo. Esta última,

8 Del Castillo Puente (2007) p. 49; García Bobadilla (2009) pp. 54-60.

9 Sobre este particular, cabe señalar que los contratos de distribución son aquellos en los que el productor o fabricante acuerda con el distribuidor el suministro de un bien para su reventa en una zona determinada. Estos contratos presentan las siguientes características: a) son celebrados entre empresarios independientes; b) son de duración continuada y; c) en estos el distribuidor actúa por cuenta propia y, por tanto, asume el riesgo empresarial de las operaciones en las que interviene.

10 En todo caso, debe asegurarse el equilibrio entre el poder negociador de las grandes superficies y la industria. Si llevásemos hasta las últimas consecuencias la fuerza que, en la práctica, tienen los distribuidores, posibilitando hasta la extenuación la proliferación de las marcas blancas, podría plantearse la desaparición de la industria, especialmente en el período de crisis económica actual que, dicho sea de paso, España está padeciendo con especial dureza.

11 El acto de vender a pérdida puede constituir, según las circunstancias concurrentes en el supuesto concreto, en el contexto del ordenamiento jurídico español, una infracción de la Ley de Defensa de la Competencia en materia antitrust, de la Ley de Competencia Desleal, de la Ley de Ordenación del Comercio Minorista en la regulación del comercio interior e, incluso, podría ser un ilícito penal.

12 Para un sector de la doctrina -Nystron (1970) pp. 50-69; Mcgoldrick (1990) p. 56-, la falta de información que el consumidor tiene, le lleva a generalizar el nivel de precios de un establecimiento en atención a unos pocos productos de referencia. Una conclusión que aquel extrae tras cotejar los precios de un establecimiento bien con su experiencia bien con los precios de otros establecimientos.

13 Tal apreciación se realiza por OTERo LASTRES (1996) pp. 1457-1466.

14 Para profundizar sobre el conocimiento de los precios por los consumidores, se recomienda la lectura, entre otros, de Gabor y Grancer (1961) pp. 170-188; Allen, Harrell y Hutt (1976) p. 21; Dickson y Sawyer (1990) pp. 42-53. 
de acuerdo con la doctrina ${ }^{15}$, puede definirse como aquel instrumento de marketing utilizado por los distribuidores al por menor, para atraer clientes a su establecimiento, junto al producto o servicio promocionado, de una ventaja adicional de gran valor.

Para determinar la existencia o no de la objetiva idoneidad del comportamiento desleal de la venta a pérdida, para inducir a engaño a los consumidores y usuarios, habrá que hacer un juicio de valor. Para ello, se tendrán en cuenta dos aspectos. Por un lado, el estándar de consumidor y de usuario al que va dirigida la conducta y, por otro, el riesgo objetivo de confusión del comportamiento para inducir a error. Lo importante para proceder a su represión no es el resultado, sino que la conducta resulte objetivamente idónea para producirlo.

La deslealtad reside, precisamente, en la realización de precios ${ }^{16}$ de reclamo a través de ventas a pérdida con la finalidad de inducir o incitar a los consumidores o usuarios a comprar o contratar otros productos o servicios del mismo establecimiento. Esta teoría, planteó un innumerable número de problemas a los fabricantes que, en el caso de España, se resolvió con la aprobación de la Ley 7/1996, de 15 de enero, de Ordenación del Comercio Minorista -LOCM-, cuyo artículo 14 se ocupa de esta interesante cuestión. Tal precepto dispone que "[n]o obstante lo dispuesto en el artículo anterior, [que alude a la libertad de precios] no se podrán ofertar ni realizar ventas al público con pérdida, fuera de los supuestos regulados en los Capitulos IV y V del Título II de la presente Ley, a menos que, quien la realice, tenga por objetivo alcanzar los precios de uno o varios competidores con capacidad para afectar, significativamente, a sus ventas, o se trate de artículos perecederos en las fechas próximas a su inutilización. En todo caso, deberá respetarse lo dispuesto en la Ley sobre Competencia Desleal ${ }^{17}$. 2. A los efectos señalados en el apartado anterior, se considerará que existe venta con pérdida, cuando el precio aplicado a un producto sea inferior al de adquisición según factura, deducida la parte proporcional de los descuentos que figuren en la misma, o al de reposición si este fuese inferior a aquel o al coste efectivo de producción si el artículo hubiese sido fabricado por el propio comerciante, incrementados, en las cuotas de los impuestos indirectos que graven la operación”.

En cualquier caso, es importante no penalizar el éxito comercial, salvo cuando se trate de prácticas incompatibles con la realización del mercado interior, como la existencia de pruebas evidentes de abuso de posición dominante en el mercado o de perjuicios para el consumidor, contraviniendo el artículo 101 del Tratado de Funcionamiento de la Unión Europea. Un mercado competitivo es una manera eficaz de proteger al consumidor y la eficiencia operativa puede suponer beneficios adicionales. En un mercado libre y equitativo, los minoristas compiten en servicio, calidad de los productos y relación calidad-precio.

Por otro lado, cabe señalar que la realización de conductas desleales perjudica no solo a los competidores, sino, además, a los consumidores. En el supuesto que en el presente estudio sometemos a examen, estos últimos se ven afectados en dos sentidos. Por un

\footnotetext{
15 En este sentido véase, Palau Ramírez (1998) p. 233.

${ }^{16}$ Dado que el precio es un elemento indicativo importante, aunque -todo hay que decirlo- no el único, el legislador ha tratado de proteger la correcta conformación de los precios, libre de prácticas desleales que lo puedan falsear, con la finalidad de defender a los consumidores y usuarios y al propio mercado. En este último sentido, véase Alonso Soto (1992) p. 85.

${ }^{17}$ La venta a pérdida es objeto de regulación en el art. 17 de la LCD. Sobre este particular, véase MASSAGUER Fuentes (2010) pp. 495-526.
} 
lado, hay actos que les perjudican directamente como los supuestos de engaño o confusión $y$, por otro, existen hechos que les lesionan, de forma indirecta, al producir una distorsión del correcto funcionamiento del sistema competitivo cual es el aprovechamiento de la reputación ajena. Todos los casos mencionados, que perjudican al consumidor, pueden producirse mediante la utilización de marcas de distribuidor que, al limitar a una marca líder, confunden al consumidor, al mismo tiempo que se aprovechan de la reputación ajena -notoriedad y prestigio alcanzado por otros fabricantes tras años de invertir en innovación y comunicación comercial ${ }^{18}$.

Según la teoría económica, un modelo competitivo perfecto y transparente implica que exista claridad en las ofertas, de manera que el consumidor sea capaz de diferenciar unas de otras. Cada oferente, según tal postulado, ha de basar su actuación en su propio esfuerzo y la libertad de decisión del consumidor no se puede ver obstaculizada. Sin embargo, debemos poner de manifiesto que el sistema competitivo no impide, en modo alguno, que los competidores puedan tener en cuenta las ofertas de sus rivales y les permite imitar todo aquello que no esté protegido por un derecho exclusivo de propiedad industrial y, de acuerdo con el artículo 4 de la Ley española 3/1991, de 10 de enero, de Competencia Desleal, tras la reforma de 2009, no sea contrario a la buena fe objetiva ${ }^{19}$.

Entendemos que gran parte de los problemas que en el sector de la distribución se suscitan podrían mitigarse y, en cierta medida, erradicarse en virtud de la autorregulación de todos los agentes que en el sector de la distribución interactúan. En base a la autodisciplina podría aprobarse un código de conducta voluntario destinado a regular las relaciones entre los minoristas y los proveedores, a nivel de cada uno de los Estados europeos, en el plano comunitario, así como la realización de un análisis detallado de la cadena de suministro, en la que, además del proveedor original y del sector de la gran distribución, intervienen muchos otros actores. Este código de conducta ofrecería a un mayor número de empresas de producción y servicios medianas o incluso pequeñas y artesanales la posibilidad de acceder a la gran distribución con un mínimo de garantías. El legislador español sugiere fomentar el recurso a tal práctica en un importante elenco de normas, destacando, a nuestros efectos, las consideraciones establecidas en la Exposición de Motivos de la LOCM.

\section{CONSIDERACIONES GENERALES ACERCA DE LAS FUNCIONES DE LA MARCA}

Una de las funciones más significativas de la marca, como es sabido, es la distintiva de los productos o servicios de una empresa de los idénticos o similares ofrecidos en el mercado por otras empresas ${ }^{20}$. Esta última función, a tenor de las resoluciones judiciales

18 En este sentido, véase Recio Menéndez, Cañabate Pozo y Rivera Gómez (1999) p. 50.

19 En relación a tal extremo, dispone Massaguer Fuentes que, respecto a la naturaleza objetiva, deben excluirse del ámbito de aplicación de la LCD aquellas conductas que resultan plenamente conformes a la finalidad institucional no concurrencial propia de su autor y de su comportamiento. Por el contrario, han de entenderse dotadas de finalidad concurrencial aquellas conductas que típicamente no son concurrenciales cuando se hallan determinadas por fines espurios. Véase MASSAGUER FUENTES (1999) pp. 124 a 126.

20 De la Fuente García (1999) p. 23; Schmitz Vaccaro (2012) p. 10. 
más relevantes del Tribunal de Justicia de la Unión Europea ${ }^{21}$, sobre el particular, debe ser entendida en el sentido de que la marca garantiza que todos los productos y/o servicios contraseñados proceden bien de su titular bien de una persona física o jurídica bajo su control (es decir, como puede colegirse, no todos provienen de la misma fuente productiva). En otras palabras, la esencia de la marca es evitar el riesgo de confusión ${ }^{22}$, ya que es básica su finalidad de distinguir productos y servicios en el mercado, de forma que el consumidor medio no los confunda con otros ${ }^{23}$. En consecuencia, no puede ser marca un signo que carezca de fuerza o capacidad distintiva o que la pierda de forma sobrevenida ${ }^{24}$ (artículo 5.1.b Ley 17/2001, de 7 de diciembre, de Marcas -en adelante LM-).

Junto a esta función, la marca puede cumplir diferentes funciones ${ }^{25}$, entre las que destacan la función publicitaria, la indicativa del nivel de calidad y la reveladora del origen empresarial del bien o servicio en cuestión ${ }^{26}$. A todas ellas nos referiremos, de forma breve, a continuación.

La marca, como decimos, puede desempeñar una función publicitaria ${ }^{27}$ al favorecer la colocación y promoción del producto o servicio marcados entre sus potenciales adquirentes y usuarios. A través de la función publicitaria de la marca, el empresario utiliza el signo para entrar y permanecer en el mercado. Se considera una función autónoma, toda vez que el signo tiene, por sí mismo, una vis atractiva sobre los consumidores que es independiente de la función indicadora del origen empresarial, del goodwill de la marca y de la información que la misma transmite. La simple repetición del signo en simples medios publicitarios convierte a la marca en un estímulo para la demanda de los productos por los consumidores.

La publicidad, en sus distintas formas y presentaciones, se ha integrado en nuestra sociedad de forma indisoluble y se ha convertido en un elemento tan cotidiano como imprescindible. Por un lado, cotidiano porque ya no se concibe un producto sin marca -aunque se trate de las denominadas marcas blancas- y, por otro, imprescindible tanto para consolidar y desarrollar el mercado como para mantener, potenciar o modificar actitudes y valores sociales. El discurso publicitario hace uso de todos los componentes de la comunicación para elabo-

\footnotetext{
21 En este sentido, véase las sugerentes sentencias: SA CNL-SUCAL NV contra HAG GF AG (1990): Tribunal de Justicia de las Comunidades Europeas, 17 de octubre de 1990 -apartado 16-; IHT Internationale Heiztechnik GmbH y Uwe Danzinger contra Ideal-Standard GmbH y Wabco Standard GmbH (1994): Tribunal de Justicia de las Comunidades Europeas, 22 de junio de 1994 -apartado 45-.

22 Por lo que se refiere a los distintos supuestos en los que concurre riesgo de confusión, puede verse Bercovitz Rodríguez-Cano (2002) pp. 88 y ss.

${ }^{23}$ La mera asociación mental o evocación de una marca por otra diversa, no parece suficiente para, por sí misma, apreciar la concurrencia de un riesgo de asociación. El consumidor, al menos, ha de entender que impera una conexión jurídica entre los titulares de ambas marcas. Véase Lobato (2002) p. 289.

${ }_{24} \mathrm{El}$ carácter distintivo de un signo puede concebirse como la aptitud que el mismo ha de tener para distinguir los productos y/o servicios que, en este sentido, identifica, respecto del resto de bienes y/o servicios similares o análogos que se ofertan en el mercado. Sobre este extremo véase, Ruipérez DE AzCÁrATE (2008) p. 54.

25 En cuanto a las funciones de la marca, véase Fernández NovoA (2004) pp. 66-79.

26 Sobre esta cuestión nos remitimos a las consideraciones efectuadas por De la Fuente García (2001) pp. 119-232.

27 Respecto a la importancia de la función publicitaria de la marca, véase Aré́n LaLín (1982) p. 59; FERNÁNDEZ-NovoA (1984) pp. 61-70.
} 
rar sus mensajes buscando siempre objetivos de información, persuasión y seducción. Este entramado de la comunicación comercial provoca que los profesionales publicitarios estudien, trabajen y construyan los códigos verbales y no verbales del mensaje para conseguir influir y atraer al receptor, tanto en sus propuestas explícitas como implícitas. El producto, la marca, los valores, los ideales, todo, en definitiva, queda imbricado en una pieza publicitaria que esconde más de lo que aparentemente muestra. En consecuencia, puede afirmarse que en todo el proceso de investigación y creación de la argumentación, posicionamiento y personalidad comercial juega un papel esencial la comunicación no verbal, ya que el simbolismo del producto/marca, los valores asociados al mismo y la mayor carga persuasiva del anuncio se encuentra esencialmente en el mensaje connotado -o lo que es lo mismo: el "no dicho", pero sí sugerido- de la publicidad. En la formación de imagen publicitaria tan esencial es la comunicación verbal -qué se dice- como la no verbal -cómo se dice-, ya que ambas influyen en el resultado y éxito final del anuncio ${ }^{28}$.

Consecuencia directa de esta función, es la "condensación" por la marca del prestigio -también denominado goodwill ${ }^{29}$ - del producto o servicio y, por efecto directo, el de su fabricante o distribuidor. Debemos poner de relieve que el goodwill incluye la buena fama o prestigio adquirido por el empresario a lo largo del tiempo en el que los productos estén en el mercado. Es preciso insistir en que esta función condensadora del prestigio empresarial no la desempeñan por igual todas las marcas. En efecto, ciertas marcas pueden ostentar un elevado goodwill, mientras que pueden existir marcas carentes de prestigio e, incluso, algunas podrán tener una mala fama o illwill $^{30}$-aunque, qué duda cabe, es difícil que una marca con mala fama pueda mantenerse en el mercado-. Sin embargo, únicamente las marcas que gozan de goodwill son marcas que pueden quedar perjudicadas por el aprovechamiento indebido de la marca o buen nombre por parte de terceros usurpadores.

La marca puede, además, cumplir una función indicativa del nivel de calidad de los productos y/o servicios que distingue. La marca, por sí sola, indica e informa a los consumidores el nivel de calidad que tienen los productos, la naturaleza de los mismos, así como sus caracteres. Para conservar la confianza del público comprador, el titular de la marca ha de ofrecer a los consumidores productos que gocen de la calidad, naturaleza o de caracteres semejantes, sin hacer alteraciones sustanciales en los mismos de suerte que por tales modificaciones resulten perjudicados. Esta función justifica que su titular pueda oponerse a la ulterior comercialización por terceros de productos que, habiendo sido introducidos en el mercado por él o con su consentimiento, hayan experimentado modificaciones o alteraciones en sus características.

Por último, la marca puede indicar el origen empresarial del producto y/o servicio distinguido. Como se ha puesto de manifiesto, tanto por parte de la doctrina como por la jurisprudencia, esta función garantiza a los consumidores que las mercancías proceden de la misma empresa o grupo de empresas. Para proteger la función que examinamos, la norma-

\footnotetext{
28 BASSAT (1993) pp. 98-100; Massó (2001) pp. 46-51.

29 El término anglosajón goodwill es traducido por la doctrina española como buena fama o elevada reputación. Véase, entre otros, Gonzalez-Bueno Catalán de Ocón (2005) p. 18; Palau Ramírez (2005) p. 20; Herrero Suárez (2006) p. 219; Otero García-Castrillón (2006) p. 49; Llobregat Hurtado (2007) p. 49-51.

30 Fernández Novoa (1978) pp. 33-62.
} 
tiva trata de evitar la convivencia de marcas confundibles ${ }^{31}$. En todo caso, cabe determinar que esta última función puede no ser cumplida en ciertos casos, en especial, cuando su uso sea licenciado aisladamente o su titularidad cedida con independencia de la totalidad o parte de la empresa. No puede afirmarse, pues, con carácter absoluto, que la marca actúe como medio indicador de la procedencia del producto signado ${ }^{32}$. En este sentido, podrá actuar como indicativo de su calidad si es que su uso por los licenciatarios es controlado por su titular. Es relevante que las partes hagan referencia a la facultad de control del licenciante en el contrato, puesto que, aunque resulta necesario para proteger la calidad y el conjunto de valores que comunica una determinada marca, no puede considerarse que sea un elemento esencial del contrato de licencia. Por tanto, al no ser un elemento natural ni inherente al contrato de licencia, no puede llevarse a cabo este examen si no está previamente previsto entre las partes. En efecto, si bien es cierto que el control de calidad es importante, para proteger la función distintiva y la función indicadora de calidad de los signos, no puede considerarse como un elemento esencial. En primer lugar, porque no está legalmente previsto, de manera que parece que el legislador deja esta cuestión a la libre decisión de las partes. En segundo lugar, porque, no estando legalmente previsto, resulta desorbitado y desmedido conceder esta facultad a todo licenciante, incluso cuando no exista pacto entre las partes contratantes, ya que, en realidad, le permite injerirse en la esfera del licenciatario. Por último, es posible interpretar que corresponde al licenciante conservar el valor de la marca para que esta desarrolle eficazmente todas sus funciones, por lo tanto, forma parte de su diligencia debida el incorporar un pacto de este tipo en el contrato de licencia ${ }^{33}$.

\section{LAS MARCAS DE DISTRIBUIDOR COMO ALTERNATIVA FRENTE A LAS PRIMERAS MARCAS}

\subsection{CONCEPTO DE MARCA BLANCA}

Podemos definir ${ }^{34}$ las marcas blancas, siendo conscientes de que no existe una terminología ${ }^{35}$ unánime para referirse al fenómeno, como aquellos productos fabricados por un deter-

\footnotetext{
31 La importancia de esta función se pone de relieve en múltiples resoluciones del Tribunal de Justicia de las Comunidades Europeas (en adelante STJCE). Así, entre otras muchas, en: SA CNL-SUCAL NV contra HAG GF $A G$ (1990): Tribunal de Justicia de las Comunidades Europeas, 17 de octubre de 1990, fundamentos 13 y 14; Canon Kabushiki Kaisa contra MetroGoldwyn Mayer Inc. (1998): Tribunal de Justicia de las Comunidades Europeas, 29 de septiembre de 1998, fundamentos 26 y 27. En esta última sentencia se recuerda la función del origen empresarial de los productos para evitar la confusión de los consumidores. Esta puede tener lugar por el hecho de que los consumidores erróneamente consideren que los productos y servicios proceden de la misma empresa o, en su caso, se trata de dos empresas vinculadas económicamente cuando, en realidad, no lo son; y Segabo Inc. y SA Ancienne Maison Dubois et Fils contra GB. Uni SA. (1999): Tribunal de Justicia de las Comunidades Europeas, 1 de julio de 1999.

32 Alonso Espinosa y Lázaro Sánchez (2002) pp. 165-206.

33 Sobre este particular, nos remitimos a CASADO CERviño (1983) pp. 154-160.

34 Mills define las marcas blancas como "una marca utilizada por un minorista o mayorista para una línea o variedad de productos bajo distribución exclusiva o controlada”. Véase Mills (1995) pp. 117.

35 Entre los términos acuñados para referirse a las marcas gestionadas por la distribución o a algunos de sus tipos se pueden mencionar, entre otros muchos: marca de distribución, marca del (de) distribuidor, marca de la distribución, marca propia, marca propia de distribución, marca propia del detallista, marca privada,
} 
minado industrial que son ofrecidos al consumidor bajo el nombre o marca del distribuidor o detallista, que es quien realiza las funciones de marketing en relación con las mismas ${ }^{36}$.

Mediante la introducción de las marcas de distribuidor -estrategia en expansión en España-, los intermediarios compiten con los productores en la generación de imagen de marca; y lo hacen con éxito, resultando cada vez más difícil a los productores diferenciarse de los intermediarios en el mercado.

Tanto el desarrollo de nuevos conceptos y productos, como la publicidad, estrategias a las que los productores han de recurrir para diferenciarse, implican unos costes que no están al alcance de todos ellos ${ }^{37}$. Es decir, cada vez resulta más costoso que los destinatarios identifiquen los productos por sus productores en el mercado, de manera que será el intermediario quien oriente al destinatario hacia el producto $^{38}$. Y es que la imagen de marca es el mejor argumento que tienen los fabricantes para negociar con los intermediarios. En efecto, el productor, a la hora de motivar al intermediario, a la adquisición del producto y de negociar con él, puede seguir dos estrategias distintas: acudir directamente al intermediario, siguiendo una estrategia de presión o bien dirigir su esfuerzo al mercado final a los destinatarios. Esto último supone adoptar una estrategia que los economistas denominan de aspiración, de manera que sean los destinatarios quienes soliciten al intermediario el producto, viéndose así este último "aspirado" por la demanda suscitada por el productor en el mercado final. Esto se consigue generando una imagen de marca entre los destinatarios ${ }^{39}$. De modo que, en un mercado con exceso de oferta, un productor sin imagen de marca es, utilizando una expresión jurídica, fungible. Y, frente a rivales tan fuertes, las estrategias de presión se vuelven contra el productor, con lo que la situación de este es netamente desfavorable.

La doctrina no es unánime en cuanto a la fecha de nacimiento de las marcas blancas. Así, según cierto sector ${ }^{40}$, las primeras marcas de distribuidor francesas tienen su origen en la segunda mitad del siglo XIX; en concreto, hacia 1874, mientras que la marca de distribuidor de Salinsbury, en Gran Bretaña, data de 1869. A juicio de otra corriente doctrinal ${ }^{41}$, las marcas blancas no datan, en absoluto, del siglo XIX sino que surgen en 1976, con el lanzamiento en Francia de los Produits Libres por la cadena Carrefour. Al principio, eran envases en blanco que estaban libres de publicidad, es decir, constituían un producto desnudo que eliminaba los gastos que se consideraban superfluos. Es importante subrayar que, en aquel momento, eran productos claramente diferenciados de las marcas tradicionales, sin posible confusión. La denominación de marca blanca ha hecho fortuna y, en la actualidad, se le continúa designando como tal, sobre todo a nivel coloquial, a pesar de que ha desaparecido como blanca.

marca blanca, marca genérica, marca cedida, marca paraguas, marca enseña, marca logo, marca cadena, marca exclusiva, contramarca, submarca, marca controlada, etc. También en inglés se emplean términos como private label, private brand, distributor brand, store brand, retailer brand, own brand, own label, house brand, generis products, exclusive products, etc. Y en francés: marque de distributeur, marques de distribution, etc.

36 Puelles Pérez, Fernández de Larrea y Albert (1997) p. 112.

37 Múgica Grijalba (1996) pp. 31-41.

38 Muñiz Martínez, Placer Galán y Cervantes Blanco (1997) p. 61.

39 Vázquez Casielles, Trespalacios Gutiérrez (1997) pp. 439-442 y 460.

40 Davara (1997) pp. 29-35; Davara (1998) pp. 39-46.

41 Vargas y Martín (1995) pp. 131-140; Ormaza (1997) pp. 40-44. 
Sin embargo, el auténtico renacimiento de las marcas de distribuidor es relativamente reciente, evidenciando, no obstante, una gran capacidad evolutiva. Ciñéndonos al mercado español, este proceso abarca dos etapas bien diferenciadas entre sí: la primera cubre la década 1977-87, en tanto que la segunda, que arranca en 1988-89, continúa vigente hoy en día. La aparición de las primeras marcas de distribuidor en España, que sigue los pasos de las experiencias francesas ${ }^{42}$, está asociada inequívocamente a una estrategia de bajo coste. Es la respuesta, en unos casos, a la posición predominante de algunos fabricantes o, más frecuentemente, a las demandas de racionalidad en el consumo por parte de una clientela que padece los efectos de tas crisis.

La misma denominación marca blanca, como hemos anticipado, resulta equívoca para gran parte de las referencias de distribuidor. De hecho, cada vez tienen más colorido comercial y hasta se publicitan con intensidad buscando asociar la imagen del detallista con los valores que encarnan sus propias marcas.

En los últimos años, los grandes distribuidores -entre los que destacan Carrefour, Mercadona, Eroski, Auchan y el Corte Inglés- han adoptado una agresiva política de promoción de productos bajo su propia marca. De esta forma, los principales distribuidores se han convertido en los primeros competidores de los fabricantes en el mercado de la distribución minorista. Tradicionalmente se ha mantenido que los costes soportados por la distribución para sus marcas propias han sido considerablemente más bajos que los tolerados por el fabricante en la comercialización de su cartera de marcas ${ }^{43}$. Sin embargo, la consolidación de las marcas de distribuidor en gran número de categorías y mercados y, en consecuencia, su importancia como herramienta clave en la negociación con el fabricante y en la fidelización del consumidor al establecimiento, han propiciado, en la actualidad, un creciente interés del distribuidor hacia sus marcas y un progresivo esfuerzo de marketing hacia las mismas. Este último se observa en diferentes frentes, entre los que, a título de ejemplo, destaca la preocupación del minorista por dotar a sus marcas propias de una mejor calidad ${ }^{44}$, en la segmentación de mercado de las marcas de distribuidor -incorporando marcas Premium de distribuidor ${ }^{45}$, en la política de merchandising aplicada a estas marcas, caracterizada por la asignación de mejores y mayores espacios en el lineal ${ }^{46}-$, en la presencia de estas marcas en nuevas categorías y en la comunicación activa de las marcas de distribuidor en el interior del establecimiento y en los medios de comunicación ${ }^{47}$.

En España, como seguidamente veremos, las marcas blancas han experimentado un crecimiento notable hasta situarse a la cabeza de los países europeos. A comienzos de los años ochenta, la cuota de mercado de la marca de distribuidor empezó a crecer, de forma significativa, en nuestro país. Según las estimaciones realizadas ${ }^{48}$ en 2001, la cuota de mer-

${ }^{42}$ El despegue de las marcas de distribuidor tiene lugar con los productos libres de Carrefour (1976). En España, las marcas blancas de Eroski hacen su aparición en agosto de 1977.

43 Gómez Suárez y Rubio Benito (2006) pp. 157-174.

${ }_{44}$ Hoch y BanerJi (1993) pp. 57-67; Halstead y Ward (1995) pp. 38-48.

45 Dunne y Narasimhan (1999) pp. 41-52.

46 Hoch (1996) pp. 89-102; Fernández y Gómez (1999) p. 39; Recio y Román (1999) p. 13.

47 Richardson, Dick y Jain (1994) p. 30.

${ }^{48}$ Dobson (2005) p. 540. 
cado en valor de las marcas blancas era del 17\% en España, una penetración moderada en comparación con otros países. En 2005, la penetración de las marcas blancas en España aumentó hasta el $26 \%$ de cuota de mercado en términos de valor. Asimismo, según los datos más recientes, provenientes de la consultora especializada Information Resources Inc. (IRI) ${ }^{49}$, entre septiembre de 2007 y el mismo mes de 2008, las enseñas respaldadas por la gran distribución han crecido más de un $8 \%$ hasta alcanzar el 32\% de las ventas totales del sector, frente al 29,6\% de hace un año. Además, esta cuota de mercado de las marcas de distribuidor tiene un crecimiento sostenido en todos los sectores, destacando el de alimentación. Durante 2008, al calor de la crisis económica, la marca blanca ha ganado cuota de mercado en todos los países de Europa, aunque en ninguno con tanta fuerza como en España. Este último, como decimos, es el país con mayor penetración de la marca blanca, por delante de países como Alemania (31\%), Holanda y Reino Unido (27\%), Francia (26\%) e Italia (13\%). Este crecimiento está siendo mucho más acusado en las marcas de distribución que en las de fabricantes y en los últimos meses esta tendencia, qué duda cabe, se está agudizando, como consecuencia de la crisis económica, si bien todavía puede ser mayor ${ }^{50}$.

Tales cifras $^{51}$ tienen importantes consecuencias para los fabricantes. En efecto, las empresas que fabrican productos de primeras marcas están acusando el crecimiento de las marcas de distribuidor. El principal efecto es una reducción del volumen de ventas, seguido por un descenso de los márgenes y por un incremento de los costes de comercialización de sus productos.

El acrecimiento de ventas de las marcas de distribuidor obedece a la mayor sensibilidad al precio de los productos, seguida del aumento de la aceptación de las marcas entre la sociedad, la mejora de la calidad de las marcas de distribuidor ${ }^{52}$ y la falta de diferenciación percibida entre las marcas de fabricante y de distribuidor. Cabe poner de relieve que los consumidores acrecientan su demanda de marcas de distribuidor ante la crisis. Sin embargo, según cierto sector doctrinal ${ }^{53}$, esta tendencia no se revierte en los períodos de expansión económica, ya que, al probar estas marcas, obtienen un nivel de satisfacción alto ${ }^{54}$.

49 Para ampliar tal información, véase el siguiente sitio Web: www.informationresources.es.

50 A juicio de Iniesta y Agustín, las futuras fusiones entre distribuidores acentuarán más, si cabe, el desarrollo de estas marcas. Iniesta y Agustín (2001) p. 108.

51 Según la Private Label Manufacturers Association, en 2009, las marcas de distribuidor representan una cuota importante en el mercado español y a nivel global, siendo la cuota de mercado española de un 34\%, una de las mayores a nivel europeo.

52 La calidad de producto es uno de los principales aspectos evaluados por los consumidores como paso previo a su elección de compra de una marca de fabricante o de distribuidor. En este sentido, pone de relieve un sector de la doctrina -Bellizi- que las diferencias en calidad entre las marcas de fabricante y de distribuidor son provocadas por la peor valoración de las marcas de distribuidor en los atributos extrínsecos. Véase BeLLIzI et al. (1981) p. 57. Sin embargo, recientemente, una determinada corriente doctrinal -Semeijn, Van Riel y Ambrosini- entiende que el diferencial de calidad objetiva entre las marcas de fabricante y las marcas de distribuidor es cada vez menor e, incluso, en ciertos supuestos la calidad de las marcas de distribuidor es superior. Véase Semeijn, Van Riel y Ambrosini (2004) p. 247.

53 Kumar y Steenkamp (2007) pp. 26-31.

54 Tal apreciación resulta destacada por el citado informe realizado entre el Instituto de Empresa y Kreab Gavin Anderson en relación a las marcas blancas. 
Las marcas del distribuidor constituyen, en definitiva, una manifestación de la descentralización productiva, ya que con las mismas se disimula la fuente productiva (identificándose la procedencia geográfica por códigos de barras ex Real Decreto español 1573/1985, de 1 de agosto, por el que se regulan las denominaciones genéricas y específicas de productos alimentarios) y se inserta únicamente la marca del distribuidor. De hecho, el titular de la marca blanca subcontrata la manufactura del producto que etiqueta con su propia marca, siendo la persona del fabricante irrelevante para el consumidor ${ }^{55}$.

\subsection{RiVALIDAD ENTRE MARCAS DE DISTRIBUIDOR Y MARCAS DE FABRICANTE}

Actualmente, en Europa -aunque en ciertos países comunitarios con más intensidad-, nos encontramos ante una profunda crisis que está impactando directamente en el bienestar familiar. Tal situación es especialmente difícil para las familias con menos recursos para el consumo, dentro de las cuales debemos entender incluidas aquellas en las que todos o parte de los miembros están en desempleo. En efecto, en el contexto económico descrito, las familias, sobre todo las de clase media, pueden verse muy afectadas por una importante disminución de los recursos económicos. Por consiguiente, la desaceleración económica y la subida de los precios provocan que muchos de los productos de gran consumo adquiridos por las unidades familiares descritas sean de la enseña de la gran distribución que, como regla general, suele ser más barata que la de los fabricantes líderes.

En relación a estos últimos, cabe indicar que los productos que cuentan con la marca de primeros fabricantes tienen un limitado margen para reducir los precios. De hecho, los grandes fabricantes no son demasiado proclives a modificar el precio, pues, entre otros aspectos, daría la impresión, frente al público consumidor, que el precio no está adaptado a los costes más la ganancia que quieren obtener. No tiene demasiado sentido que en época de crisis los fabricantes líderes bajen los precios y en momentos de bonanza los suban, ya que podría pensarse que los beneficios no están ajustados al mercado. En consecuencia, los productos de los fabricantes líderes son muy insensibles a la crisis, dado que, según tal postura, el precio constituye un determinante de la calidad. Como alternativa frente a las primeras marcas, el consumidor dispone de las marcas blancas o del distribuidor, especialmente valoradas en contextos de dificultad económica. El gran distribuidor, sin dejar de ser tal, se aventura en la tarea de introducir productos en el mercado por dos caminos: bien haciendo un producto al que le dan la marca del propio distribuidor bien creando una marca blanca para todos sus productos. Aunque tales conductas están dentro de la legalidad, si bien, todo hay que decirlo, hay una cierta confusión entre fabricación y distribución.

Respecto a este último extremo, cabe manifestar que las marcas blancas son productos fabricados por un determinado industrial, pero que terminan siendo comercializados bajo la marca de un tercero (el distribuidor) que aparece como fabricante del mismo frente al consumidor final. Dado que la comercialización de las marcas blancas se efectúa bajo el paraguas - prestigio comercial, solvencia empresarial, responsabilidad jurídica- de quien pone esos productos en el mercado, cobra sentido el hecho de que no se restrinja la facultad del verdadero fabricante para autorizar la distribución y venta de esos mismos produc-

55 Fernández Nogales (2000) p. 75. 
tos, pero bajo la marca de un tercero incluso en el mismo ámbito geográfico reconocido a otro u otros de sus clientes marquistas ${ }^{56}$.

Aunque el recurso a las marcas blancas, por parte de los distribuidores, es una práctica completamente lícita, pueden suscitarse, como veremos en los dos apartados siguientes, ciertos problemas, a tenor de la normativa española de defensa de la competencia y de la legislación en materia de competencia desleal. Aunque, insistimos, de ello nos ocuparemos más adelante, cabe adelantar, por cuanto en este momento interesa, que un tema en el que pueden plantearse ciertas dificultades de índole legal viene determinado por el hecho de que el distribuidor presente, bajo la denominación de su propia marca, su producto, que no debe olvidarse que es alternativo al del fabricante líder, con una forma de presentación muy similar al de este último. En el caso que planteamos, se ven afectadas algunas de las funciones de la marca que, como se recordará, vimos en el segundo apartado del presente estudio. En efecto, como decimos, la función indicadora del origen empresarial se ve parcialmente desdibujada. También podrá ser seriamente abatida la función identificadora de la calidad, ya que existe la posibilidad de que el fabricante del gran distribuidor elabore un producto sin la misma calidad que la del primer fabricante. Finalmente, podrá, asimismo, verse perjudicada la función del goodwill. Si estas tres funciones enunciadas, de una u otra manera, se ven, por decirlo en términos coloquiales, tocadas también se verá afectada la función identificativa y publicitaria del mercado. Para que la situación descrita no se suscite, los fabricantes líderes se están lanzando a la carrera de proyectar campañas publicitarias en las que ponen de relieve que no fabrican para otros, revelando, con tal actuación, que sus productos no podrán encontrase bajo la denominación de ninguna marca blanca. En otros términos, tal campaña comercial pretende advertir al consumidor de la posibilidad de que existan productos - de marcas blancas o no- similares al suyo, pero que, en todo caso, presentan un origen empresarial diverso. La agresiva actividad publicitaria de los grandes fabricantes, para reivindicar la marca de fábrica, es consecuencia de la fortísima competencia que están sufriendo en el mercado por parte de las marcas de distribuidor.

La marca no surge sin los consumidores. De aquí que el signo, al ser asociado a determinados productos o servicios, pone en movimiento todo un proceso mental en el público consumidor, en torno al origen empresarial, calidad y aún respecto de la buena fama de las mercancías a las que la mencionada marca hace alusión, tutelando no solo el privativo interés del empresario, sino, en general, el del consumidor. Sobre este particular, cabe profundizar, en el tema que nos ocupa, destacando el hecho de que las marcas blancas debilitan la asociación que existe entre el signo relativo a la marca del fabricante líder y la actitud que el consumidor manifiesta frente a la misma, creando, de este modo, una suerte de marca parasitante, dado que existe una especie de parasitación, por parte de la marca blanca, del prestigio de la gran marca que progresivamente va debilitando a la del gran fa-

56 El fabricante se asegura la no concurrencia con ninguno de sus clientes, pero ninguna razón comercial o atinente a la libre competencia ha de impedirle que consienta la presencia de varios de esos marquistas en una misma área o zona comercial. Estos, en definitiva, no actúan en el mercado externamente a modo de intermediarios del fabricante -a diferencia de las figuras del agente/representante o del concesionario/ distribuidor-, sino que prefieren hacerlo en cualidad de fabricantes, sujetándose, por tanto, a las reglas de la libre competencia con quien decide actuar de igual modo. 
bricante. La crisis afecta a la transparencia del mercado porque desdibuja las marcas líderes, ya que, como hemos visto, da origen a marcas - marcas de distribuidor- que ostentan peculiaridades dignas de examen.

Resulta interesante plantear una cuestión en relación a las marcas blancas que es si las mismas podrían ser consideradas engañosas. Si se entendiera que inducen a error, podría solicitarse la caducidad de la marca por ser engañosa. No debe olvidarse que para que se produzca la caducidad de la marca, por su conversión en engañosa, es preciso que la marca deje de cumplir con su función diferenciadora. El engaño existe, a título de ejemplo, cuando un signo provoca en la mente del consumidor una idea distorsionada acerca de la naturaleza del producto, su procedencia, sus características, su modo de fabricación u otras informaciones que induzcan al público a error.

\subsection{LA NECESARIA OBSERVANCIA DE LA NORMATIVA DE DEFENSA DE LA COMPETENCIA}

En un mercado competitivo, las empresas de la distribución que así lo deseen, tienen libertad para integrarse verticalmente y competir con los fabricantes en igualdad de condiciones, para satisfacer los deseos de los consumidores, aunque, todo hay que decirlo, tal actuación suponga desreferenciar los productos de un proveedor para hacer sitio a los productos de su propia marca ${ }^{57}$. Las conductas que el distribuidor efectúe pueden resultar plenamente lícitas, si bien, por el contrario, en algunos supuestos, como en el presente apartado veremos, pueden vulnerar la Ley española 15/2007, de 3 de julio, de Defensa de la Competencia ${ }^{58}$.

En la actualidad, como hemos visto, las marcas blancas ocupan altísimas cuotas de mercado en numerosas categorías y compiten intensamente con las marcas del fabricante por el espacio en el lineal y por atraer las preferencias del consumidor. En cualquier caso, las empresas que disfrutan de una posición dominante colectiva en los mercados de aprovisionamiento y distribución minorista pueden, como habitualmente acontece en la práctica, subcontratar la producción de un producto bajo la denominación de la marca creada por el distribuidor para designar sus propios productos -integración parcial-, pero deben asegurar una igualdad de oportunidades a las marcas del fabricante frente a sus propias marcas, para que sea la decisión del consumidor la que determine el éxito y la rentabilidad de un producto. Solo así se garantiza el bienestar de los consumidores, evitando que los grandes distribuidores decidan unilateralmente los productos que deben ser consumidos.

Como venimos determinando, el distribuidor con poder de mercado debe realizar una gestión de categoría objetiva y no discriminatoria para respetar la normativa de defensa de la competencia. Esta objetividad podría presumirse si, por ejemplo, la gestión de la categoría $^{59}$ se realizase por un departamento distinto al que gestiona la marca del distribuidor o

\footnotetext{
57 La negativa de referenciación o la desreferenciación de un proveedor, así como su sustitución por una marca blanca, debe justificarse por criterios predeterminados, objetivos y no discriminatorios. En caso contrario, podremos encontrarnos ante un abuso de posición dominante por parte del distribuidor.

58 En relación a esta norma, véase la sugerente obra de Folguera Crespo, Gutiérrez Hernández, Massaguer Fuentes y Sala Arquer (2010).

59 La gestión de la categoría por parte del distribuidor (precios, publicidad, posicionamiento, etc.) debe seguir, como decimos, criterios predeterminados, objetivos y no discriminatorios.
} 
un experto independiente, cuyo informe de carácter pericial podría servir de referencia para evaluar el respecto de los principios de objetividad, no discriminación y competencia por parte del distribuidor.

En el ámbito español, sobre todo en bienes de consumo diario, es patente la existencia de una posición dominante colectiva de las tres empresas líderes en el mercado de la distribución minorista: Carrefour, Mercadona y Eroski. Aunque la adquisición de una posición dominante, individual o colectiva, no es sancionable, sí lo es, por el contrario, cualquier manifestación abusiva de la misma. En este caso, los tres distribuidores citados han recurrido a diversas estrategias para reducir la competencia ${ }^{60}$, entre ellas en el mercado de aprovisionamiento y beneficiar sus marcas blancas en perjuicio de las marcas de los proveedores ${ }^{61}$.

Desde la perspectiva del Derecho de la competencia, la introducción de marcas blancas puede tener efectos ambiguos sobre la competencia en dos aspectos. Por un lado, la integración vertical del distribuidor puede generar mayor eficiencia -ahorro de costes de transacción- y competencia en el mercado de los fabricantes y de la distribución -diferenciación de productos-. Por otro, la integración vertical sitúa al distribuidor en una posición privilegiada frente al resto de los fabricantes, transformándose así en un agente doble que puede perjudicar a los productos del fabricante y beneficiar los suyos. La distribución, asimismo, tiene la última palabra en relación a la presencia de un producto de marca de fabricante en sus lineales y, en particular, su presentación y precio. Este poder puede tentar a la distribución a llevar a cabo una estrategia de sustitución de los productos de marca del fabricante ${ }^{62}$. Debe, por consiguiente, tomarse conciencia del riesgo de que el distribuidor abuse de su poder de mercado para excluir a la marca del fabricante en beneficio de su propia marca o para reducir la competencia entre las marcas de la categoría, sin generar ningún beneficio para los consumidores. En definitiva, ha de destacarse el inconmensurable poder que, en la actualidad, ostenta la distribución.

\footnotetext{
60 El mercado de la distribución de bienes de consumo diario ostenta una estructura realmente muy concentrada (oligopolio). El liderazgo español de los tres distribuidores líderes -Carrefour, Mercadona y Eroski- determina conductas paralelas (colusión tácita) que limitan la competencia en el mercado de aprovisionamiento $y$, además, de distribución minorista. Las empresas oligopolistas ostentan una posición dominante colectiva y sus conductas colusivas pueden dar lugar a abusos prohibidos por la normativa de defensa de la competencia.

61 Respecto a tales conductas, que restringen la competencia, a tenor del Tribunal Vasco de Defensa de la Competencia, en su estudio "La distribución de bienes de consumo diario: competencia oligopolio y colusión tácita”, disponible en: <http://www.ogasun.ejgv.euskadi.net/r51-14000/es/contenidos/informacion/imformes_ mercados/es_infomerc/adjuntos/090420\%20DISTRIBUCION\%20COMERCIAL\%2020\%20ABRIL\%20 $2009 \% 20$ FINAL.pdf>, son los tres grandes bloques de supuestos: paralelismo de precios en la distribución minorista que restringe la competencia y genera una tendencia inflacionista de los bienes de consumo diario; paralelismo en las negociaciones con los proveedores orientado a obtener pagos y condiciones comerciales ventajosas; y paralelismo en la subcontratación de productos de fabricantes para su reventa como marca propia (marca blanca) y un tratamiento discriminatorio de los productos de marca de los fabricantes en término de referenciación, posicionamiento y precio.

62 Sobre este particular, cabe determinar que la Australia Competition and Comerce Comisión (en el informe sobre la distribución minorista y las relaciones con los proveedores operado en 2008) ha detectado que algunos distribuidores han rechazado pagos promocionales ofrecidos por los proveedores con la única finalidad de proteger las ventas de sus productos de marca blanca. Tal institución entiende que la realización de este tipo de prácticas, por parte de empresas con poder de mercado, constituye un claro abuso de posición dominante.
} 
En un entorno de intensa competencia minorista, la gestión de la categoría por el propio distribuidor es una garantía de que el surtido, la presentación y los precios respondían a las preferencias de los consumidores. Sin embargo, en un entorno de competencia imperfecta caracterizado por el poder de mercado de las grandes empresas de la distribución (posición dominante colectiva) y la presencia de marcas blancas, la gestión de la categoría por el distribuidor presenta los mismos o mayores riesgos de conflicto de interés y resultados competitivos que la gestión de la categoría por un proveedor con poder de mercado. $Y$ es que no debe olvidarse que la gestión de la categoría debe ir encaminada a cumplir su finalidad originaria, que no es otra que aumentar la rentabilidad de la categoría, y no a ampliar la rentabilidad de la marca del fabricante. El incremento de la rentabilidad de la categoría refleja un aumento del bienestar del consumidor, mientras que el aumento de la rentabilidad de la marca de distribuidor manifiesta una reducción del bienestar del consumidor y, al implicar también una transferencia de rentas de marcas más eficientes a la marca blanca, una reducción del bienestar total.

Uno de los caracteres más destacados de las problemáticas que rodean las relaciones distribuidores-proveedores es que nos hallamos ante una casi absoluta inexistencia de pronunciamientos jurisprudenciales porque, aunque las prácticas abusivas existen, no se denuncian, por el temor a las represalias -y las consecuentes pérdidas económicas para el proveedor- que previsiblemente tendrán para el fabricante que, hasta la fecha, ningún potencial demandante se ha atrevido a superar.

La Federación de Industrias de Alimentación y Bebidas (FIAB) y la Asociación Española de Distribuidores, Autoservicios y Supermercados (ASEDAS) en 2007 firmaron un Acuerdo sobre Recomendaciones de Buenas Prácticas Comerciales para la Mejora de la Gestión en la Cadena de Valor y el Fomento de la Cooperación Empresarial (denominado Acuerdo ASEDAS-FIAB). Tal convenio es un código de conducta voluntario que establece los principios rectores de las negociaciones comerciales entre proveedores y distribuidores, que otorga mayor seguridad jurídica a los proveedores en relación a diversos aspectos de la relación comercial como las promociones comerciales, la logística (entrega, recepción y, en su caso, devolución), los servicios y cargos del distribuidor y los plazos de pago. Tales códigos están siendo objeto de adopción en diferentes países del entorno europeo ${ }^{63}$. Así, cabe destacar que en el Reino Unido, la Comisión Nacional de la Competencia adoptó un código de buenas prácticas para los distribuidores con poder de mercado en sus relaciones

\footnotetext{
${ }^{63}$ Debemos destacar que la necesidad de fomentar la autorregulación en el sector de la distribución y que, en virtud de la misma, se aprueben códigos de conducta de alcance nacional, ha sido sugerida por diferentes instancias comunitarias. En este sentido, el Comité Económico y Social Europeo en el dictamen del relativo a "La evolución de la gran distribución y su impacto en proveedores y consumidores" de 3 de diciembre de 2008 (para cuya lectura se recomienda la consulta del Diario Oficial de la Unión Europea de 28 de julio de 2009). Las consideraciones presentes en el citado dictamen son especialmente interesantes, por cuanto, entre otros extremos, se indican los posibles contenidos que el código de conducta que se aprobara podría incluir. Asimismo, cabe determinar que, en el caso que se susciten eventuales conflictos, se sugiere la intervención de un mediador con facultades para recabar información de todas las partes implicadas y para investigar, de forma preventiva, las infracciones del código de conducta.
} 
con los proveedores que en estos momentos está ampliando ${ }^{64}$, al tiempo que se propone nombrar un defensor del consumidor para vigilar su cumplimento.

La creación de un código de buenas prácticas elaborado por los grandes distribuidores minoristas, a nivel nacional, podría interpretarse como una invitación a coaligarse entre ellos, lo que, de hecho, iría en detrimento de la competencia. No obstante, la política oficial debe consistir en examinar estos códigos y asegurarse de que aumentan la transparencia y la diligencia debida tanto del minorista como del proveedor, beneficiando también a largo plazo al consumidor.

El código de buenas prácticas establece una serie de recomendaciones con el objetivo de mejorar las negociaciones comerciales entre las empresas alimentarias, fabricantes y distribuidoras, que deberán basarse en los principios de motivación de actos, formalización de los acuerdos y publicidad de las condiciones generales de contratación. También se hace mención a la modificación de tarifas, así como a las variaciones de los impuestos, tasas y otros gravámenes y a las aportaciones de los sistemas integrados de gestión que se produzcan durante el período de vigencia de los acuerdos comerciales. Además, se establece que las empresas deberán asegurar que sus órganos y/o delegaciones territoriales cumplan los acuerdos comerciales que les afecten, evitando que la falta de información sobre los mismos sea alegada para vulnerarlos. El Acuerdo ASEDAS-FIAB prevé el establecimiento de un Comité de Seguimiento que, a su vez, designará un Comité de Resolución de Conflictos.

El documento que analizamos es complementario del marco legal por el cual se rige el sector. Por ello, se refuerza el compromiso de las empresas del sector alimentario español por cumplir adecuadamente la normativa vigente. Entre las actuaciones que se vigilarán especialmente, destaca el cumplimento de normas, como la prohibición de venta con pérdida o la venta por debajo del precio de coste, facilitándose, igualmente, la labor inspectora de la Administración Pública. Además, en relación a la normativa de plazos de pago máximos, tanto la distribución como la industria acuerdan, y así lo expresan en este código de conducta, que la autoridad competente más adecuada para velar por su cumplimento sea aquella en la que está domiciliado el fabricante. El cumplimiento de esta propuesta ahorrará trámites innecesarios a la industria española, que comercializa sus productos en todas las Comunidades Autónomas.

El fenómeno de la autorregulación, en virtud de la cual son posibles los códigos de conducta, supone la observancia de unas pautas de conducta - principios y normas éticascuyo cumplimiento previamente se ha fijado como objetivo. Simultáneamente, también

${ }^{64}$ La Comisión de la Competencia del Reino Unido en el informe sobre las cadenas de alimentación, publicado en mayo de 2008, entiende que las grandes empresas de distribución del sector alimentario de tal país están ofreciendo un buen servicio a los consumidores, pero, a su juicio, son necesarias medidas para incrementar la competencia en los mercados regionales y reequilibrar las relaciones entre estas empresas y sus proveedores. Entre las actuaciones concretas que se han de efectuar, se incluye modificar el código de conducta relativo a las relaciones entre los proveedores y las empresas para ampliarlo, incluyendo entre otras medidas: la prohibición a los detallistas de realizar modificaciones de los acuerdos con sus proveedores con carácter retroactivo o responsabilizar a los mismos por las mermas; previsión del arbitraje obligatorio para resolver cualquier diferencia que esté dentro del ámbito del código de conducta; y, por último, la obligación de comunicar detalladamente las razones por las que se reduce significativamente el volumen de negocio con un proveedor o se suspenden las relaciones comerciales. 
constituye la expresión del compromiso de responsabilidad social de un determinado sector de la industria. En los últimos años, somos testigos y, en ciertos casos, protagonistas de un vigoroso impulso, fomentado desde diversas instancias, del soft law o Derecho no vinculante especialmente por lo que respecta a la protección de los consumidores y/o usuarios en numerosos ámbitos entre los que destacan los que, en este momento, analizamos. El Derecho no vinculante o voluntario es el conjunto de instrumentos que, aunque no ostentan el carácter imperativo que caracterizan a las normas jurídicas, pueden afectar, de manera significativa, al panorama legislativo, promoviendo la estandarización legal de determinadas prácticas.

En base a que la autorregulación es una práctica más informal que la legislación y que carece de capacidad coactiva -entendida esta en el sentido de una virtualidad y alcance cercano a la estatal-, la eficacia de la misma puede ser muy débil si no se da la organización de todas las partes implicadas. Hay que observar, asimismo, que la autorregulación no puede ser vista como una excusa que exima al Poder Legislativo de sus obligaciones, sino como complemento a una legislación que, inevitablemente, no puede dejar de tener un carácter muy general y ambiguo. Podemos, de esta manera, afirmar, en cierto sentido, que la profesionalización del sector empresarial conduce a su autorregulación.

Aunque, como seguidamente veremos, el código de conducta no está exento de ciertas críticas, merece, en líneas generales, una valoración positiva, dado que, entre otros aspectos, constituye el primer acuerdo aprobado voluntariamente por los principales eslabones de la cadena alimentaria, a saber: los distribuidores y los fabricantes. En todo caso, como previamente anunciamos, debemos ser conscientes de que nos encontramos ante un acuerdo estrictamente voluntario, fruto de la vigencia del principio de la autonomía de la voluntad reconocido en el ordenamiento jurídico español en el artículo 1255 del Código civil. Aunque, de acuerdo con el artículo 1091 del mismo cuerpo legal enunciado, las obligaciones que nacen de los contratos tienen fuerza de ley entre las partes contratantes, y deben cumplirse al tenor de los mismos, estamos en un ámbito especialmente peculiar. En efecto, el poder del distribuidor resulta extraordinariamente superior al de cualquier fabricante, por lo que los incumplimientos del articulado contenido en tal documento, a nuestro juicio, no serán denunciados ante el Comité de seguimiento para que este, a su vez, nombre la comisión que se encargará de resolver extrajudicialmente el conflicto.

En efecto, la experiencia de ciertos países -caso, por ejemplo, de Australia- pone de relieve que los códigos de conducta se enfrentan a un incumplimiento generalizado por parte de las empresas de la distribución y una aversión, igualmente, de los proveedores a denunciarlo. Aunque los códigos de buenas prácticas comerciales deben, como hemos anticipado, valorarse de manera positiva, no impiden la colusión tácita de los grandes distribuidores, con la colaboración de los proveedores con poder de mercado, encaminada a extraer de los proveedores pagos comerciales elevados a costa de soportar precios de cesión más elevados. Esta conducta colusiva restringe la competencia en el mercado de los fabricantes y en el mercado de la distribución minorista.

En definitiva, si bien los códigos de conducta, como el Acuerdo ASEDAS-FIAB, desprovistos de cláusulas anticompetitivas, suponen un intento plausible de fomentar relaciones comerciales leales entre proveedores y distribuidores, la función de las autoridades 
de competencia es velar por la competencia y el bienestar de los consumidores. La existencia de una posición dominante colectiva de los tres grandes distribuidores españoles por excelencia, como Carrefour, Mercadona y Eroski, en el mercado de aprovisionamiento y de prácticas paralelas tendentes a restringir la competencia en el mercado de los fabricantes y la distribución, hace necesaria la intervención de las autoridades de competencia para fijar los criterios de aplicación de la Ley de Defensa de la Competencia en este ámbito.

\subsection{EL RESPETO DE LA LEGISLACIÓN EN MATERIA DE COMPETENCIA DESLEAL}

Las marcas blancas, aunque constituyen un fenómeno lícito, en determinados supuestos, pueden llegar a vulnerar la normativa no solo de defensa de la competencia -como ya hemos visto en el apartado anterior- sino, además, de competencia desleal. En efecto, por lo que a este último aspecto respecta, cabe la posibilidad de que el distribuidor de la marca blanca en cuestión presente sus productos con una forma de presentación muy similar a la que tienen los de fabricantes líderes. De hecho, la creación de un riesgo de confusión es el acto más antiguo de competencia desleal, pues impide la diferenciación de productos. Como seguidamente veremos, hay un aprovechamiento de la reputación ajena al acercar la imagen global del producto de la marca blanca al de la marca conocida.

La situación que se produce en esta clase de conflictos en los que el hecho denunciado es susceptible de calificarse, simultáneamente, como ilícito marcario y concurrencial, trae a colación la complementariedad relativa de los textos legales reguladores de ambos, la Ley de Marcas española (LM) y la Ley española 3/1991, de 10 de enero, de Competencia Desleal (LCD), y la necesidad de huir de la más pura aplicación del principio de especialidad, tendente a la preponderancia de una u otra norma, sobre todo en supuestos en los que la legislación marcaria se muestre reacia a amparar los signos supuestamente vulnerados. Y todo ello pese a no olvidar los distintos objetivos que los mismos persiguen ${ }^{65}$, pues mientras la LM tiende a proteger un derecho subjetivo sobre un bien inmaterial, de naturaleza real, aunque especial, eficaz erga omnes y concedido por su registro, la LCD no tiene como fin, al menos directamente, amparar al titular de la marca. En efecto, como señala la Exposición de Motivos de esta última, no pretende resolver conflictos entre competidores, sino "ser un instrumento de ordenación de conductas en el mercado", siendo los destinatarios de su protección, en consecuencia, no los titulares de los signos, ni los empresarios, sino todos los que participan en el mercado, incluso, qué duda cabe, los consumidores y el mercado.

Los litigios que, en la práctica, se plantearán entre las marcas blancas y las marcas de los fabricantes líderes, en los supuestos que venimos planteando, podrán situarse en la órbita de los artículo 6 y 12 de la LCD. Tales preceptos regulan la imitación confusoria de signos distintivos (creaciones formales), mientras que, por otro lado, el artículo 11 de la citada ley acoge en su seno la imitación de productos (prestaciones o servicios).

\footnotetext{
65 A pesar de esa diversidad de fines, entre las dos Leyes existe una recíproca tensión, dado que, por un lado, la utilización de un signo constituye una actuación en el mercado y tiene un fin concurrencial y, por otro, el riesgo de confusión del consumidor (cuya protección no está ausente en la Ley de Marcas) constituye, a la vez, el núcleo de la infracción del derecho sobre la marca y de algunos ilícitos concurrenciales -artículos 6, 11.2 y 12 LCD-.
} 
El artículo 6 de la LCD, a la manera que lo hiciera el artículo 10 bis del Convenio de la Unión de París, considera desleal "todo comportamiento que resulte idóneo para crear confusión con la actividad, las prestaciones o el establecimiento ajenos", siendo bastante, a tales efectos, la existencia de "riesgo de asociación por parte de los consumidores respecto de la procedencia de la prestación".

La llamada competencia parasitaria que establece el artículo 12 LCD comprende aquellas conductas conducentes a un aprovechamiento indebido de la reputación de signos distintivos ajenos de cualquier clase (marcas, nombres comerciales, denominaciones de origen, indicaciones de procedencia, etc.), en beneficio propio o ajeno, reputando su párrafo segundo particularmente desleal "el empleo de signos distintivos ajenos o de denominaciones de origen falsas acompañados de la indicación acerca de la verdadera procedencia del producto o de expresiones tales como "modelo": "sistema", "tipo", "clase" y similares".

El objeto de la confusión que nos ofrecen estos preceptos viene referido a la que se produce en relación con los medios de identificación utilizados por un empresario en el mercado, bien sea de su actividad, de sus productos o prestaciones o de su establecimiento comercial. Es decir, el que recae sobre la identificación o presentación de aquellos o estos, no tratándose de un concepto puramente normativo, ya que no puede generarse riesgo de confusión si no existe un uso efectivo del signo y cierta implantación en el mercado. Por ello, el juicio de confundibilidad habrá de pasar, necesariamente, por la comparación, no solo de los signos y de los productos o servicios entre los cuales se suscite la polémica, sino por el examen de otra serie de circunstancias, tales como los precios de los citados productos, los canales de distribución de los mismos, la publicidad efectuada, etc., referencias que coadyuvan a reforzar, debilitar e, incluso, a eliminar el riesgo de confusión.

El riesgo de confusión que dichos preceptos tratan de proscribir -que no es sino el riesgo de confundibilidad, esto es, la mera posibilidad de que el mismo se produzca, aunque no se haya ocasionado todavía- ha de interpretarse, tras la amplitud con que lo diseñan la Primera Directiva Comunitaria de 21 de diciembre de 1988, relativa a la aproximación de las legislaciones de los Estados miembros en materia de marcas (artículo 4.1.b) y el Reglamento (Comité Ejecutivo) núm. 40/94 del Consejo, de la Marca Comunitaria ${ }^{66}$ -artículos 8.1.b) y 9.1.b)-, aplicable también al ámbito concurrencial, con un criterio holgado, comprensivo también del riesgo de asociación. Este último se origina cuando el consumidor no sufre una confusión acerca de la identidad de la empresa de procedencia, sino que, aún consciente de que los productos distinguidos con los signos en cuestión tienen una procedencia empresarial distinta, supone equivocadamente que, entre las empresas oferentes de cada uno de ellos, existen relaciones económicas, comerciales, organizativas o de cualquier otra. Resulta destacable que se ha declarado repetidamente, por parte de la jurisprudencia ${ }^{67}$, que el juicio de confundibilidad entre los diversos signos confrontados ha

\footnotetext{
${ }_{66}$ Tal disposición fue objeto de modificación por el Reglamento (CE) no 1653/2003 del Consejo, de 18 de junio de 2003.

${ }^{67} \mathrm{La}$ jurisprudencia, en base a distintas normativas, ha brindado protección al envase, botella y etiquetas (de la bebida alcohólica BayLeys) en las sentencias: R. and A. BAYLEYS and Co. Ltd. contra Licorería Abeldense SL (1993): Tribunal Supremo, 19 de mayo de 1993 y R. \& A. Bailey Company Limited contra Montara, SA (1994): Tribunal Supremo, 29 de octubre de 1994; el envase, forma y colores del bote (Colacao) en Ollé, SA contra
} 
de alcanzarse a través de una visión de conjunto sintética, de la totalidad de los elementos integrantes de los mismos, sin descomponer su unidad fonética ${ }^{68}$ y gráfica y que las semejanzas, de haberlas, es preciso que estén referidas, no solo a los elementos individualizados de cada una de las marcas, sino también y principalmente a la generalidad o conjunto de las distintas partes que comprenden la misma -en este sentido Nutrexpa, SA contra Nutrec, SA (1995): Tribunal Supremo, 16 de mayo de 1995-.

La determinación de la semejanza o similitud entre dos signos constituye una función atribuida, en principio, a los tribunales que conocen en instancia, pero, como se trata de un concepto jurídico indeterminado, es preciso observar las pautas para su apreciación establecidas por las Sentencias del Tribunal de Justicia de las Comunidades Europeas (TJCE) y la doctrina jurisprudencial. El Tribunal Supremo español viene declarando que el criterio analítico y comparativo efectuado en la instancia debe mantenerse, salvo que sus decisiones sean contrarias a la lógica o al buen sentido ${ }^{69}$. El buen sentido supone logicidad, coherencia y racionalidad, y la semejanza ha de tener la entidad suficiente para crear el riesgo de confusión de los consumidores, lo que exige calibrar todas aquellas circunstancias que, en conexión con el signo expresivo de cada marca, puedan tener influencia en la

Nutrexpa, SA (1998): Tribunal Supremo, 23 de febrero de 1998; y la ha tratado específicamente, aunque no ha apreciado que se diera el riesgo de confusión, en R. Seelig and Hille Kommanditgesellschaft contra don Antonio G. N. y Ben-Hur, SA (1997): Tribunal Supremo, 8 de mayo de y Procter y Gamble de España, SA y Richardson-Vicks Inc. contra Sociedad Química de Perfumería y Color, SA (1997): Tribunal Supremo, 5 de junio de 1997.

68 Tiene reiteradamente declarado el Tribunal Supremo que en el tráfico mercantil prevalece el aspecto verbal sobre todos los demás elementos integrados en la marca, porque es de aquella manera oral, y con referencia exclusiva a la denominación, como los productos son ordinariamente demandados por el consumidor. Tal doctrina se encuentra establecida, entre otras muchas, en las sentencias: Sin identificación de partes (1986): Tribunal Supremo, 27 de noviembre de 1986; F.O.H.G., contra Registro de la Propiedad Industrial (1987): Tribunal Supremo, 14 de diciembre de 1987; Entidad Mercantil D., S. A., contra Editorial XX Debate (1988): Tribunal Supremo, 23 de julio de 1988; Sin identificación de partes (1990): Tribunal Supremo, 4 de enero de 1990; Nutrexpa, SA contra Nutrec, SA (1995): Tribunal Supremo, 16 de mayo de 1995; K, SA contra Registro de la Propiedad Industrial (1996): Tribunal Supremo, 11 de noviembre de 1996; José Sánchez Peñate, SA contra Registro de la Propiedad Industrial (1996): Tribunal Supremo, 19 de diciembre de 1996; Bayer, AG contra el Registro de la Propiedad Industrial (2000): Tribunal Supremo, 22 de marzo de 2000; Kabushiki Kaisha Toshiba contra el Registro de la Propiedad Industrial (2000): Tribunal Supremo, 4 de abril de 2000; Unite Biscuits (UK) Limited contra el Registro de la Propiedad Industrial (2000): Tribunal Supremo, 5 de julio de 2000; Productos del Café, SA contra el Registro de la Propiedad Industrial (2000): Tribunal Supremo, 12 de diciembre de 2000; Gallaher Limited contra el Registro de la Propiedad Industrial (2001): Tribunal Supremo, 27 de junio de 2001; Ocean, SpA contra el Registro de la Propiedad Industrial (2002): Tribunal Supremo, 21 de marzo de 2002; Caja España de Inversiones, Caja de Ahorros y Monte de Piedad contra la Oficina Española de Patentes y Marcas (2004): Tribunal Supremo, 7 de julio de 2004; Inabonos, SA contra la Oficina Española de Patentes y Marcas (2005): Tribunal Supremo, 7 de abril de 2005; Mead Johnson And Company contra la Oficina Española de Patentes y Marcas (2006): Tribunal Supremo, 7 de marzo de 2006; Promociones Turísticas La Sella, SA contra la Oficina Española de Patentes y Marcas (2007): Tribunal Supremo, 30 de abril de 2007; Gallaher Limited contra la Oficina Española de Patentes y Marcas (2008): Tribunal Supremo, 7 de mayo de 2008; y Grupo It Deusto, SL contra la Oficina Española de Patentes y Marcas (2008): Tribunal Supremo, 30 de noviembre de 2008.

69 Así, entre otras muchas, las sentencias: Levi Strauss \& Co. contra Textil Conquense, SA (2000): Tribunal Supremo, 20 de julio de 2000; Sony Kabushiki Kaisha contra Macsony SL (2003): Tribunal Supremo, 26 de junio de 2003; Balpri, SL contra Chanel, SA (2005): Tribunal Supremo, 7 de octubre de 2005; Pepe (UK) Limited contra D. Blas y D. Ramón (2006): Tribunal Supremo, 28 de julio de 2006; Pepe (UK) Ltd. contra Liwe Española, SA (2006): Tribunal Supremo, 21 de diciembre de 2006; y Calzados Crube contra Adidas Salomon AG y Adidas España, SA (2007): Tribunal Supremo, 25 de enero de 2007. 
posible confusión que en el mercado pueda producirse por la identidad de los productos ${ }^{70}$, existiendo el riego de confusión estricto cuando se da lugar a la errónea creencia de que las prestaciones proceden de la misma empresa, y amplio si se supone equivocadamente que el producto procede de empresas que son diferentes pero pertenecen a una misma estructura u organización global ${ }^{71}$.

Son muy escasas las resoluciones judiciales en las que se analiza la posible deslealtad de actuaciones realizadas por los distribuidores - para comercializar la marca blanca- consistentes en imitar los envases ideados para ciertos productos por fabricantes líderes. Uno de los pocos casos que, sobre el particular, existen es el que fue resuelto en Nutrexpa, $S A$ contra Chocolates Hosta Dulcinea, SA y Lidl Autoservicio Descuento, SA (2002): Audiencia Provincial de Barcelona, 28 de junio de 2002. El supuesto de hecho sometido a enjuiciamiento versaba sobre el lanzamiento de un producto por la demandada (Lidl) a base de cacao en polvo distinguido y envasado en un bote cilíndrico de fondo amarillo en el que se apreciaban figuras de personajes de color negro portadoras de producto evocando al cacao que comercializa la demandante (Nutrexpa). Nos encontramos ante una presentación confundible por sus colores y demás elementos que lo componen con la presentación del producto de la marca Cola Cao, existiendo, por consiguiente, riesgo de confusión ${ }^{72}$.

La presentación del envase comercializado por la demandada que, como hemos anticipado, era la conocida Lidl (bote circular de iguales medidas y formato que el que distingue el producto de la actora -Nutrexpa-, de color amarillo, con letras azules y con los clásicos personas de color que popularizara aquella) evoca indudablemente al célebre producto Cola Cao. Todo incita a pensar que nos hallamos ante un artículo próximo a este (envase de igual color, tamaño y forma, en el que aparecen unas figuras muy parecidas y en idéntica actitud), sin que puedan servir para desvirtuar este extremo las circunstancias de que el color amarillo sirva usualmente para identificar o reconocer este tipo de productos en polvo derivados del cacao o que, tras el requerimiento efectuado por la actora, las demandadas

70 En este sentido, las sentencias: Pepe Textiles España SA y Pepe UK Ltd contra Liwe Española SA (2003): Tribunal Supremo, 29 de septiembre de 2003; Mariano y la entidad Bodegas Rodero SL contra Explotaciones Valduero, SA (2006): Tribunal Supremo, 26 de enero de 2006; Pepe (UK) Limited contra D. Blas y D. Ramón (2006): Tribunal Supremo, 28 de julio de 2006; y Compañia Española de Petróleos, S.A. (Cepsa) contra DEPOGAS, S.L. e INDU-VIMAR S.L. (2007): Tribunal Supremo, 17 de julio de 2007.

${ }^{71}$ Sobre este particular nos remitimos a Balpri, SL contra Chanel, SA (2005): Tribunal Supremo, 7 de octubre de 2005 .

72 Un supuesto de hecho muy similar fue objeto de enjuiciamiento en Ollé, SA contra Nutrexpa, SA (1998): Tribunal Supremo, 23 de febrero de 1998. Nutrexpa demandó a la entidad Ollé SA -fabricante de las marcas de distribuidor "Día", "Delpuy", "Charter" y "Simago"- como consecuencia de la imitación, por parte de esta última, de los botes en los que se contenía cacao en polvo, consistentes en un envase con tapa roja y cuerpo amarillo, semejantes y confundibles con los de Cola Cao que es comercializado por Nutrexpa. Tal producto era precisamente objeto de venta en grandes cadenas de distribución como Día perteneciente a Carrefour. El recurso de casación interpuesto por Ollé SA fue desestimado, confirmándose, por parte del Tribunal Supremo, el fallo dictado en segunda instancia que, a su vez, ratifica, en gran parte, la resolución de instancia reconociendo la violación del derecho exclusivo sobre marca que Nutrexpa posee, así como la existencia de un acto de competencia desleal, condenando Ollé SA a que cesase en dicha violación, así como a retirar del tráfico comercial los envases aludidos, material publicitario y etiquetas en que se reflejen aquellos, aunque se hallen en poder de terceros a quienes se haya suministrado, y, finalmente, a indemnizar los daños y perjuicios ocasionados. 
modificasen el color de la tapa del bote, que dejó entonces de ser colorada, como la que exhibe Cola Cao, para pasar a ser azul. Por otro lado, no puede aducirse que los canales de distribución de ambos productos sean distintos y que el que ha sido puesto en controversia con el de la recurrente -Nutrexpa- conforme una típica marca blanca comercializada por la entidad demandada -Lidl-solamente en sus establecimientos, pues, como determina la resolución, "ello impediría la confusión si no se vendiese en ellos el fabricado por la actora, cosa que no ha sido acreditada como cierta".

En todo caso, el Tribunal termina revocando la sentencia dictada en primera instancia -en la que se desestimaba la demanda presentada por Nutrexpa frente al distribuidor Lidl por la que se perseguía la declaración de deslealtad del comportamiento que hemos enunciado-, declarando que la actividad de la demandada consistente en la comercialización de un producto a base de cacao en polvo con un envase de presentación que por sus características, es confundible con la presentación del producto marca Cola Cao de la actora. En consecuencia, condena a Lidl a cesar en el envasado y en la comercialización del producto (denominado Golden Sur) en un bote confundible por sus colores y demás elementos con el antedicho producto y a retirar del mercado a su costa la existencia del mismo.

\section{CONCLUSIONES}

Las marcas de distribuidor (que constituyen una opción en auge en la actual cesta de la compra de un importante número de consumidores) pueden definirse como aquellos productos fabricados por un determinado industrial que son ofrecidos al consumidor bajo el nombre o marca del distribuidor o detallista, que es quien realiza las funciones de marketing en relación con las mismas. El gran distribuidor, sin dejar de ser tal, se aventura en la tarea de introducir productos en el mercado por dos caminos: bien haciendo un producto al que le dan la marca del propio distribuidor bien creando una marca blanca para todos sus productos. Como alternativa frente a las primeras marcas, el consumidor dispone de las marcas blancas o del distribuidor, especialmente valoradas en contextos de dificultad económica.

Las diversas funciones que la marca puede desempeñar-distintiva, publicitaria, la indicativa del nivel de calidad y la reveladora del origen empresarial del bien o servicio en cuestión- se ven desdibujadas en el caso de las marcas blancas.

En efecto, como decimos, la función indicadora del origen empresarial se ve parcialmente difuminada. También podrá ser seriamente abatida la función identificadora de la calidad, ya que existe la posibilidad de que el fabricante del gran distribuidor elabore un producto sin la misma calidad que la del primer fabricante. Finalmente, podrá, asimismo, verse perjudicada la función del goodwill. Si estas tres funciones enunciadas, de una u otra manera, se ven, por decirlo en términos coloquiales, tocadas también se verá afectada la función identificativa y publicitaria del mercado.

Para que la situación descrita no se suscite, los fabricantes líderes se están lanzando a la carrera de proyectar campañas publicitarias en las que ponen de relieve que no fabrican para otros, revelando, con tal actuación, que sus productos no podrán encontrase bajo la denominación de ninguna marca blanca. En otros términos, tal campaña comercial pretende advertir al consumidor de la posibilidad de que existan productos - de marcas blancas o 
no- similares al suyo, pero que, en todo caso, presentan un origen empresarial diverso. La agresiva actividad publicitaria de los grandes fabricantes para reivindicar la marca de fábrica es consecuencia de la fortísima competencia que están sufriendo en el mercado por parte de las marcas de distribuidor.

Aunque el recurso a las marcas blancas, por parte de los distribuidores, es una práctica completamente lícita, pueden suscitarse ciertos problemas a tenor de la normativa española de defensa de la competencia y de la legislación en materia de competencia desleal.

Uno de los caracteres más destacados de las problemáticas que rodean las relaciones distribuidores-proveedores es que en España nos hallamos ante una casi absoluta inexistencia de pronunciamientos jurisprudenciales relativos a las eventuales violaciones de la Ley 15/2007, de 3 de julio, de Defensa de la Competencia, porque, aunque las prácticas abusivas existen, no se denuncian, por el temor a las represalias -y las consecuentes pérdidas económicas para el proveedor- que previsiblemente tendrán para el fabricante que, hasta la fecha, ningún potencial demandante se ha atrevido a superar.

En cuanto a la posible vulneración de la normativa imperante en materia de competencia desleal -Ley 3/1991, de 10 de enero, de Competencia Desleal-, cabe la posibilidad de que el distribuidor de la marca blanca en cuestión elabore sus productos con una forma de presentación muy similar a la que tienen los de fabricantes líderes. En tal caso, hay un aprovechamiento de la reputación ajena al acercar la imagen global del producto de la marca blanca al de la marca conocida.

Entendemos que gran parte de los problemas que en el sector de la distribución se suscitan -sobre todo en materia de defensa de la competencia y de competencia deslealpodrían mitigarse y, en cierta medida, erradicarse en virtud de la autorregulación de todos los agentes que en el sector de la distribución interactúan. En virtud de la autodisciplina, podría aprobarse un código de conducta voluntario destinado a regular las relaciones entre los minoristas y los proveedores en el ámbito de cada uno de los Estados europeos, en el plano comunitario, así como la realización de un análisis detallado de la cadena de suministro, en la que, además del proveedor original y del sector de la gran distribución, intervienen muchos otros actores. Este código de conducta ofrecería a un mayor número de empresas de producción y servicios medianas o, incluso, pequeñas y artesanales la posibilidad de acceder a la gran distribución con un mínimo de garantías.

\section{BIBLIOGRAFÍA CITADA}

Allen, John; Harrell, Gilbert y Hutt, Michael (1976): Price awareness study (Washington, The Food Marketing Institute).

Alonso Espinosa, Francisco José y Lázaro Sánchez, Emilio Jesús (2002): "El nuevo Derecho de marcas (Ley 17/2001 de 7 de diciembre)", Anales de Derecho de la Universidad de Murcia, No 20: pp. 165-206.

Alonso Soto, Ricardo (1992): "Supuestos de competencia desleal por venta a pérdida y discriminación”, en Bercovitz Rodríguez-Cano, Alberto (coord.), La regulación contra la competencia desleal en la Ley de 10 de enero de 1991 (Madrid, BOE y Cámara de Comercio e Industria de Madrid) pp. 85-102. 
Areán Lalín, Manuel (1982): "En torno a la función publicitaria de la marca”, Actas de Derecho Industrial, tomo 8: pp. 57-84.

BASSAT, Luis (1993): El libro rojo de la publicidad (Barcelona, Folio).

Bellizi, Joseph; Krueckeberg, Harry; Hamilton, John y Martin, Warren (1981): "Consumers Perceptions of National, Private and Generic Brands", Journal of Retailing, vol. 57, No 4: pp. 56-70.

Bercovitz Rodríguez-Cano, Alberto (2002): Introducción a las marcas y otros signos distintivos en el tráfico económico (Navarra, Aranzadi).

Casado Cerviño, Alberto (1983): "Relieve del control en la licencia de marca", Actas de Derecho Industrial y Derecho de Autor, tomo 9: pp. 154-160.

Davara, Alicia (1997): "Marcas de distribuidor. Objetivo: fidelizar", Distribución Actualidad, No 252: pp. 29-35.

Davara, Alicia (1998): "Marcas de distribuidor. Ascenso imparable”, Distribución Actualidad, No 266: pp. 39- 46.

Dawson, John y Frasquet Deltoro, Marta (2006): "Factores determinantes del nuevo papel de la distribución minorista en Europa", Tendencias de la distribución comercial en el ámbito internacional: ICE, enero-febrero, No 828: pp. 11-24.

De la Fuente García, Elena (1999): El uso de la marca y sus efectos jurídicos (Madrid, Marcial Pons).

De la fuente García, Elena (2001): "Signos distintivos", en o'Callaghan Muñoz, Xavier (coord.), Propiedad Industrial. Teoría y Práctica (Madrid, Editorial Ramón Areces) pp. 119-232.

Del Castillo Puente, Ángel María (2007): Respuesta Eficiente al Consumidor. Gestione con Exito Las Relaciones entre Fabricantes y Distribuidores (Madrid, Netbiblo).

Dickson, Peter y SAWYer, Alan (1990): "The price knowledge and search of supermarket shoppers", Journal of Marketing, vol. 54: pp. 42-53.

Dobson, Paul (2005): "Exploiting Buyer Power: Lessons from the British Grocery Trade", Antitrust Law Journal, vol. 72, No 2: pp. 529-562.

Dunne, David y Narasimhan, Chakravarthi (1999): “The New Appeal of Private Labels", Harvard Business Review, vol. 77, No 3: pp. 41-52.

Fernández Nogales, Ángel (2000): "Las marcas de primer precio: ¿Segundas marcas de distribuidor?”, Distribución y Consumo, No 53: pp. 75-87.

Fernández NovoA, Carlos (1978): "Las funciones de la marca", Actas de Derecho Industrial y Derecho de Autor, tomo 5, Año 75: pp. 33-62.

Fernández Novoa, Carlos (1984): Fundamentos de Derecho de Marcas (Madrid, Montecorvo) pp. 61-70.

Fernández NovoA, Carlos (2004): Tratado sobre Derecho de Marcas (Madrid, Marcial Pons).

FernándeZ, Ángel y Gómez, Mónica (1999): "Estructura y distribución de espacio en el lineal: estrategias de las marcas de distribuidor en alimentación y droguería-perfumería”, Distribución y Consumo, No 45: pp. 30-49.

Folguera Crespo, Jaime; Gutiérrez Hernández, Alfonso; Massaguer Fuentes, Josép y Sala Arquer, José Manuel (2010): Comentario a la Ley de Defensa de la Competencia (Madrid, Thomson Civitas). 
Gabor, Andre y Grancer, Clive (1961): "On the price consciousness of consumer", Applied Statistics, vol 10, No 11: pp. 170-188.

García Bobadilla, Luís María (2009): “¿Necesitan los fabricantes a los distribuidores?”, MK: Marketing + Ventas, No 246: pp. 54-60.

Gómez SuÁrez, Mónica y Rubio Benito, Natalia (2006): "Gestión minorista de las marcas de distribuidor: producto y merchandising", Tendencias de la Distribución Comercial en el Ámbito Internacional: ICE, No 828: pp. 157-174.

Gómez, Carmen (1995): "La gestión del surtido por categorías de productos", Distribución y Consumo, No 24: pp. 26-30.

González-Bueno Catalán de Ocón, Carlos (2005): Marcas notorias y renombradas en la ley y la jurisprudencia (Madrid, La Ley).

Halstead, Diane y Ward, Cheryl (1995): "Assessing the Vulnerability of Private Label Brands", Journal of Product \& Brand Management, vol. 4, No 3: pp. 38-48.

Herrero SuÁrez, Carmen (2006): Los contratos vinculados (tying agreements) en el derecho de la competencia (Madrid, La Ley).

Hoch, Stephen (1996): "How Should National Brands Think About Private Labels?", Sloan Management Review, vol. 37, No 2: pp. 89-102.

Hoch, Stephen y Banerji, Shumeet (1993): "When do Private Labels Succeed?", Sloan Management Review, vol. 34, No 4: pp. 57-67.

Iniesta, Fernando y Agustín, Antonio (2001): Fidelización de consumidores (Barcelona, Gestión 2000).

Kumar, Nirmalya y Steenkamp, Jan-Benedict (2007): Private Label Strategy; How to Meet the Store Brand Challenge (Boston, Harvard Business Press).

Llobregat Hurtado, María Luisa (2007): Temas de propiedad industrial (Madrid, La Ley).

Lobato, Manuel (2002): Comentario a la Ley 17/2001, de marcas (Madrid, Civitas).

Massaguer Fuentes, Josep (2010): Comentario a la Ley de Competencia Desleal (Madrid, Thomson-Civitas).

Massó, Ramón (2001): La cultura light (Barcelona, Cims).

McGoldrick, Peter (1990): Retail marketing (Londres, McGraw Hill).

Mills, Belinda (1995): "Own Label Products and the "Lookalike" Phenomenon: A Lack of Trade Unfair Competition Protection”, European Intellectual Property Review, No 3: pp. 116-132.

Múgica Grijalba, José Miguel (1996): "Procesos de integración vertical y de estabilización de las relaciones en los canales de comercialización", Distribución y Consumo, No 30: pp. 31-41.

Muñiz Martínez, Norberto; Placer Galán, José Luis y Cervantes Blanco, Miguel (1997): "Diversificación e internacionalización de las empresas de distribución comercial que operan en España”, Distribución y Consumo, No 37: pp. 58-69.

Muñoz, Carlos (1994): "Eroski, la decisión de hacer marca propia”, $M K+$ Ventas para directivos, vol. 140, No 30: pp. 12-16.

Nystron, Harry (1970): "Retail pricing: an integrated economic and psychological approach", Economic Research Unit. Stockholm School of Economics. 
Ormaza, Iñaki (1997): "Las marcas propias en el umbral del nuevo siglo", Código 84, No 63: pp. 40-44.

Otero García-Castrillón, Carmen (2006): El comercio internacional de medicamentos (Madrid, Dykinson).

Otero Lastres, José Manuel (1996): "La venta con pérdida tras la entrada en vigor de la Ley de Ordenación del Comercio Minorista de 15 de enero de 1996”, La Ley, No 2: pp. 1457-1466.

Palau Ramírez, Felipe (1998): Descuentos promocionales. Un análisis desde el Derecho contra la competencia desleal y la normativa de ordenación del comercio (Madrid, Marcial Pons).

Palau Ramírez, Felipe (2005): La obligación de uso de la marca (Valencia, Universitat de Valencia y Tirant lo Blanch).

Puelles Pérez, José Antonio; Fernández de Larrea, Paula y Albert, Ricardo (1997): "Marcas de distribuidor: especial referencia al precio", Distribución y Consumo, No 33: pp. 112-129.

Recio Menéndez, Manuel; Cañabate Pozo, Rosario y Rivera Gómez, Daniel (1999): "Protección jurídica de las marcas de distribuidor", Distribución y Consumo, No 54: pp. 50-59.

Recio, Manuel y Román, María Victoria (1999): "Posibilidades de gestión estratégica de las marcas de distribuidor", Distribución y Consumo, No 45: pp. 13-29.

Richardson, Paul; Dick, Alan y Jain, Arun K. (1994): "Extrinsic and Intrinsic Cue Effects on Perceptions of Store Brand Quality", Journal of Marketing, vol. 58, No 4: pp. 28-36.

Ruipérez de AzCÁrate, Clara (2008): El carácter distintivo de las marcas (Madrid, Reus).

Ruzo Sanmartín, Emilio; Díez de Castro, José Alberto; Barreiro Fernández, Begoña y Losada Pérez, Fernando (2004): "Radiografía del sector comercial minorista en Galicia”, Revista Galega de Economía, junio-diciembre, vol. 13, № 2: pp. 1-31.

Schmitz Vaccaro, Christian (2012): "Distintividad y uso de las marcas comerciales", Revista Chilena de Derecho, vol. 39, No 1: pp. 9-31.

Semeijn, Janjaap; Van Riel, Allard y Ambrosini, Ana Beatriz (2004): "Consumer Evaluations of Store Brands: Effects of Store Image and Product Attributes", Journal of Retailing and Consumer Services, No 11: pp. 247-258.

VARgas, Alfonso y Martín, José Ángel (1995): "La marca en el contexto de la dirección estratégica", Revista Europea de Dirección y Economía de la Empresa, vol. 4, No 2: pp. 131-140.

Vázquez Casielles, Rodolfo y Trespalacios Gutiérrez, Juan Antonio (1997): Distribución comercial: estrategias de fabricantes y detallistas (Madrid, Civitas).

\section{NORMAS CITADAS}

EUROPA:

Tratado de Funcionamiento de la Unión Europea de 25 de marzo de 1957. Diario Oficial de la Unión Europea, 30 de marzo de 2010 (versión consolidada). 
Directiva 89/104/CEE del Consejo, de 21 de diciembre de 1988, relativa a la aproximación de las legislaciones de los Estados miembros en materia de marcas. Diario Oficial de la Unión Europea, 11 de febrero de 1989.

Reglamento 40/94 del Consejo, de 20 de diciembre de 1993, sobre la Marca Comunitaria. Diario Oficial de la Unión Europea, 15 de diciembre de 1995.

Reglamento 1653/2003 del Consejo, de 18 de junio de 2003, por el que se modifica el Reglamento 40/94 sobre la Marca Comunitaria. Diario Oficial de la Unión Europea, 29 de septiembre de 2003.

\section{ESPAÑA:}

Código civil aprobado por Real Decreto de 24 de julio de 1889. Boletín Oficial del Estado de 25 de julio de 1889

Real Decreto 1573/1985, de 1 de agosto, por el que se regulan las denominaciones genéricas y específicas de productos alimentarios. Boletín Oficial del Estado de 6 de septiembre de 1985.

Ley 3/1991, de 10 de enero, de Competencia Desleal. Boletín Oficial del Estado de 11 de enero de 1991.

Ley 7/1996, de 15 de enero, de Ordenación del Comercio Minorista. Boletín Oficial del Estado de 17 de enero de 1996.

Ley 17/2001, de 7 de diciembre, de Marcas. Boletín Oficial del Estado de 8 de diciembre de 2001.

Ley 15/2007, de 3 de julio, de Defensa de la Competencia. Boletín Oficial del Estado de 4 de julio de 2007.

Ley 29/2009, de 30 de diciembre, por la que se modifica el régimen legal de la competencia desleal y de la publicidad para la mejora de la protección de los consumidores y usuarios. Boletín Oficial del Estado de 31 de diciembre de 2009.

\section{JURISPRUDENCIA CITADA}

\section{UNIÓN EUROPEA:}

SA CNL-SUCAL NV contra HAG GF AG (1990): Tribunal de Justicia de las Comunidades Europeas, 17 de octubre de 1990 (Libre circulación de mercancías, Derecho de marca). Diario Oficial de la Unión Europea, 13 de noviembre de 1990.

IHT Internationale Heiztechnik GmbH y Uwe Danzinger contra Ideal-Standard GmbH y Wabco Standard GmbH (1994): Tribunal de Justicia de las Comunidades Europeas, 22 de junio de 1994 (Libre circulación de mercancías, Fraccionamiento de una marca debido a una cesión voluntaria, Riesgo de confusión). Diario Oficial de la Unión Europea, 6 de agosto de 1994.

Canon Kabushiki Kaisa contra MetroGoldwyn Mayer Inc. (1998): Tribunal de Justicia de las Comunidades Europeas, 29 de septiembre de 1998 (Riesgo de confusión, Similitud entre productos o servicios). Diario Oficial de la Unión Europea, 7 de noviembre de 1998.

Segabo Inc. y SA Ancienne Maison Dubois et Fils contra GB. Uni SA. (1999): Tribunal de Justicia de las Comunidades Europeas, 1 de julio de 1999 (Marca, Agotamiento del de- 
recho del titular de una marca, Consentimiento del titular). Diario Oficial de la Unión Europea, 28 de agosto 1999.

\section{ESPAÑA:}

Sin identificación de partes (1986): Tribunal Supremo, 27 de noviembre de 1986 (marcas, similitud fonética), cita Westlaw Aranzadi RJ 1986/7092.

F.O.H.G., contra Registro de la Propiedad Industrial (1987): Tribunal Supremo, 14 de diciembre de 1987 (marcas, diferencias de productos, elemento mitigador del rigorismo en la comparación), cita Westlaw Aranzadi RJ 1987/9122.

Entidad Mercantil D., S. A., contra Editorial XX Debate (1988): Tribunal Supremo, 23 de julio de 1988 (marcas, similitud fonética y gráfica: existencia), cita Westlaw Aranzadi RJ 1988/6386.

Sin identificación de partes (1990): Tribunal Supremo, 4 de enero de 1990 (letras del alfabeto: no son por sí mismas signos distintivos por no poderse monopolizar, permitiéndose solo su acceso al Registro cuando tengan especiales características gráficas, marca gráfica y marca gráfico-denominativa), cita Westlaw Aranzadi RJ 1990/604.

$R$. and A. BAYLEYS and Co. Ltd. contra Licorería Abeldense SL (1993): Tribunal Supremo, 19 de mayo de 1993 (marcas: la semejanza debe referirse no solo a los elementos individualizados de la marca sino también al conjunto de las distintas partes que comprende), cita Westlaw Aranzadi RJ 1993/3804.

R. \& A. Bailey Company Limited contra Montara, SA (1994): Tribunal Supremo, 29 de octubre de 1994 (marcas, protección legal), cita Westlaw Aranzadi RJ 1994/8098.

Nutrexpa, SA contra Nutrec, SA (1995): Tribunal Supremo, 16 de mayo de 1995 (marca, prohibiciones, semejanzas fonéticas y gráficas), cita Westlaw Aranzadi RJ 1995/4080.

K, SA contra Registro de la Propiedad Industrial (1996): Tribunal Supremo, 11 de noviembre de 1996 (propiedad industrial, materia casuística y particular, imposibilidad de hacer declaraciones generales aplicables a todos los casos), cita Westlaw Aranzadi RJ $1996 / 7968$.

José Sánchez Peñate, SA contra Registro de la Propiedad Industrial (1996): Tribunal Supremo, 19 de diciembre de 1996 (marcas, finalidad, semejanza, criterios para determinarla preferente), cita Westlaw Aranzadi RJ 1996/9272.

R. Seelig and Hille Kommanditgesellschaft contra don Antonio G. N. y Ben-Hur, SA (1997): Tribunal Supremo, 8 de mayo de 1997 (propiedad industrial, dibujos industriales y marcas, acción de nulidad por semejanza fonética y gráfica), cita Westlaw Aranzadi RJ $1997 / 3877$.

Procter y Gamble de España, SA y Richardson-Vicks Inc. contra Sociedad Quimica de Perfumería y Color, SA (1997): Tribunal Supremo, 5 de junio de 1997 (competencia desleal: doctrina general, libre imitación de prestaciones e iniciativas empresariales ajenas: excepciones, imitación y confusión), cita Westlaw Aranzadi RJ 1997/4608.

Ollé, SA contra Nutrexpa, SA (1998): Tribunal Supremo, 23 de febrero de 1998 (marcas: acción de cesación de la violación del derecho), cita Westlaw Aranzadi RJ 1998/1164. 
Bayer, AG contra el Registro de la Propiedad Industrial (2000): Tribunal Supremo, 22 de marzo de 2000 (marcas: semejanza fonética y gráfica, criterios para determinarla), cita Westlaw Aranzadi RJ 2000/1923.

Kabushiki Kaisha Toshiba contra el Registro de la Propiedad Industrial (2000): Tribunal Supremo, 4 de abril de 2000 (acceso registral: semejanza fonética o gráfica con otros ya existentes en el mercado provocando confusión, estudio comparativo entre marcas), cita Westlaw Aranzadi RJ 2000/1854.

Unite Biscuits (UK) Limited contra el Registro de la Propiedad Industrial (2000): Tribunal Supremo, 5 de julio de 2000 (marcas: inscripción registral, semejanza fonética y gráfica), cita Westlaw Aranzadi RJ 2000/7350.

Levi Strauss \& Co. contra Textil Conquense, SA (2000): Tribunal Supremo, 20 de julio de 2000 (marcas: facultades del titular de la marca, prohibiciones: semejanza fonética y gráfica, criterios para la determinación de su existencia, acción de cesación de la violación del derecho), cita Westlaw Aranzadi RJ 2000/6888.

Productos del Café, SA contra el Registro de la Propiedad Industrial (2000): Tribunal Supremo, 12 de diciembre de 2000 (marcas: acceso registral, distintivos que por su semejanza fonética y gráfica con otros ya registrados puedan inducir a error o confusión en el mercado), cita Westlaw Aranzadi RJ 2001/56.

Gallaher Limited contra el Registro de la Propiedad Industrial (2001): Tribunal Supremo, 27 de junio de 2001 (marcas: supuestos de acceso registral, semejanza fonética o gráfica con otras ya registradas), cita Westlaw Aranzadi RJ 2001/5391.

Ocean, SpA contra el Registro de la Propiedad Industrial (2002): Tribunal Supremo, 21 de marzo de 2002 (marcas: acceso registral, los distintivos que por su semejanza fonética o gráfica con otros ya registrados puedan inducir a error o confusión en el mercado), cita Westlaw Aranzadi RJ 2002/2751.

Nutrexpa, SA contra Chocolates Hosta Dulcinea, SA y Lidl Autoservicio Descuento, SA (2002): Audiencia Provincial de Barcelona, 28 de junio de 2002 (competencia desleal, riesgo de confusión), cita Westlaw Aranzadi JUR 2004/14073.

Sony Kabushiki Kaisha contra Macsony SL (2003): Tribunal Supremo, 26 de junio de 2003 (marcas: prohibiciones, semejanza fonética y gráfica, criterios para la determinación de su existencia), cita Westlaw Aranzadi RJ 2003/4265.

Pepe Textiles España SA y Pepe UK Ltd contra Liwe Española SA (2003): Tribunal Supremo, 29 de septiembre de 2003 (competencia desleal, existencia: la similitud fonética y conceptual de los signos produce o puede producir confusión en el consumidor), cita Westlaw Aranzadi RJ 2003/6399.

Caja España de Inversiones, Caja de Ahorros y Monte de Piedad contra la Oficina Española de Patentes y Marcas (2004): Tribunal Supremo, 7 de julio de 2004 (marcas, supuestos de acceso registral, los distintivos que por su semejanza fonética o gráfica con otros ya registrados puedan inducir a error o confusión en el mercado), cita Westlaw Aranzadi RJ $2004 / 4186$.

Inabonos, SA contra la Oficina Española de Patentes y Marcas (2005): Tribunal Supremo, 7 de abril de 2005 (marcas, supuestos de acceso registral), cita Westlaw Aranzadi RJ $2005 / 3213$. 
Balpri, SL contra Chanel, SA (2005): Tribunal Supremo, 7 de octubre de 2005 (marcas, acción de nulidad), cita Westlaw Aranzadi RJ 2005/8765.

Mariano y la entidad Bodegas Rodero SL contra Explotaciones Valduero, SA (2006): Tribunal Supremo, 26 de enero de 2006 (marcas, signos semejantes a los de una marca anteriormente solicitada o registrada, apreciación en cada caso mediante un estudio analítico comparativo), cita Westlaw Aranzadi RJ 2006/418.

Mead Johnson And Company contra la Oficina Española de Patentes y Marcas (2006): Tribunal Supremo, 7 de marzo de 2006 (marcas, caducidad de la oponente, efectos, declaración sobrevenida a la solicitud de inscripción), cita Westlaw Aranzadi RJ 2006/1759.

Pepe (UK) Limited contra D. Blas y D. Ramón (2006): Tribunal Supremo, 28 de julio de 2006 (marcas, prohibiciones, semejanza con otra marca anterior, acción de nulidad), cita Westlaw Aranzadi RJ 2006/6584.

Pepe (UK) Ltd. contra Liwe Española, SA (2006): Tribunal Supremo, 21 de diciembre de 2006 (marcas, acción de nulidad), cita Westlaw Aranzadi RJ 2006/9207.

Calzados Crube contra Adidas Salomon AG y Adidas España, SA (2007): Tribunal Supremo, 25 de enero de 2007 (propiedad industrial, prescripción por tolerancia), cita Westlaw Aranzadi RJ 2007/2778.

Promociones Turísticas La Sella, SA contra la Oficina Española de Patentes y Marcas (2007): Tribunal Supremo, 30 de abril de 2007 (marcas: supuestos de acceso registral), cita Westlaw Aranzadi RJ 2007/4392.

Compañia Española de Petróleos, S.A. (Cepsa) contra DEPOGAS, S.L. e INDU-VIMAR S.L. (2007): Tribunal Supremo, 17 de julio de 2007 (marcas, acción de cesación de la violación del derecho), cita Westlaw Aranzadi RJ 2007/5140.

Gallaher Limited contra la Oficina Española de Patentes y Marcas (2008): Tribunal Supremo, 7 de mayo de 2008 (marcas, supuestos de acceso registral), cita Westlaw Aranzadi RJ $2008 / 2636$.

Grupo It Deusto, SL contra la Oficina Española de Patentes y Marcas (2008): Tribunal Supremo, 30 de noviembre de 2008 (marcas, supuestos de acceso registral), cita Westlaw Aranzadi RJ 2008/4589. 